\title{
Anaesthesia for Maxillo Facial Surgery
}

\author{
Rebecca Jacob, Subramanyam S. Mahankali, \\ Renita Maria, Suman Ananathanarayana, Garima Sharma, \\ and Mary Thomas
}

\subsection{Introduction}

Maxillofacial surgery encompasses a wide range of procedures on the head and neck, combining oral and facial procedures with the ear, nose and throat (ENT), plastic surgery, neurosurgery and base of skull specialities. It ranges from simple dental extractions to complex reconstructive and free flap surgery.

Patients of all age groups may present for maxillofacial surgery. The main issues involve managing a shared airway; providing good access to head, neck and oral cavity. The management of difficult airways and measures to reduce tissue bleeding and oedema, both intra- and post-operatively pose a unique challenge to the anaesthetist. Good communication between all members of the team is essential [1].

\subsection{Preoperative Assessment}

All patients should be assessed preoperatively and an anaesthetic plan should be formulated as these patients may have a suspected or a known difficult airway or are undergoing complex or prolonged surgery. Patients may give the history of poor oral intake and nutritional state due to pain, dysphagia and odynophagia. If dyspnoea is present, it should be evaluated as to whether it is cardiac or respiratory in origin.

Electronic Supplementary Material The online version of this chapter (https://doi.org/10.1007/978-981-15-1346-6_7) contains supplementary material, which is available to authorized users.

R. Jacob $(\bowtie) \cdot$ S. S. Mahankali · R. Maria · S. Ananathanarayana · G. Sharma

Department of Anesthesiology, Columbia Asia Referral Hospital, Yeshwantpur, Bangalore, Karnataka, India

M. Thomas

Department of Anesthesiology, Regional Cancer Centre, Medical College Campus, Thiruvananthapuram, Kerala, India
Previous surgeries, medication history and comorbidities diagnosed earlier should be noted. Medication history is important in all patients, especially elderly patients with cardiac, respiratory or renal involvement. It is also important to ascertain whether the patients have any comorbid ailments like hypertension, diabetes, thyrotoxicosis or myxoedema, a history of epistaxis or bleeding tendency and use of anticoagulants $[2,3]$.

\subsubsection{Patients on anticoagulants}

Patients on anticoagulants may present for emergency or elective surgery. The type of anticoagulant the patient is on should be noted during pre-operative assessment. Risk of peri-operative bleeding versus thrombosis on discontinuation of anticoagulants should be stratified and accordingly discontinued or bridged with preferably unfractionated heparin or low-molecular-weight heparin prior to elective surgery. Usually, three half-lives $\left(\mathrm{T}_{1 / 2}\right)$ discontinuation of anticoagulants prior to surgery is considered optimal to prevent blood loss (Table 7.1) [3].

In emergency situations, the main goals are discontinuation of anticoagulation, delaying semi-urgent procedures as appropriate and employment of reversal strategies like plate-

Table 7.1 Recommendations for discontinuation of anticoagulation prior to elective surgery

\begin{tabular}{l|l} 
Drug & Time of discontinuation \\
\hline Warfarin & 5 days \\
\hline $\begin{array}{l}\text { Factor Xa inhibitors } \\
\text { Rivaroxaban } \\
\text { Apixaban }\end{array}$ & $\begin{array}{l}>24 \mathrm{~h} \\
\text { ROCKET AF } \geq 3 \text { days } \\
\text { Low bleed risk } \geq 24 \mathrm{~h} \\
\text { High bleed risk } \geq 48 \mathrm{~h}\end{array}$ \\
$\begin{array}{l}\text { Low-molecular-weight heparin } \\
\text { Prophylactic } \\
\text { Therapeutic dose }\end{array}$ & $\begin{array}{l}12 \mathrm{~h} \\
\mathrm{~h}\end{array}$ \\
\hline
\end{tabular}

American College of Chest Physician 2012 Guidelines published in Chest, the RE-LY trial published in Circulation 2014, the ROCKET AF trial, and the manufacturer's recommendations 
let transfusions, fresh frozen plasma, vitamin $\mathrm{K}$ antagonists, and prothrombin complex concentrates.

The previous anaesthetic charts should be reviewed for the techniques used, ease of mask ventilation, best direct laryngoscopy grade, Endotracheal tube (ETT) size used, and any difficulties encountered and should be noted. The airway of previously operated patients may be altered due to previous surgeries and/or oedema, so this should be taken into account while reviewing the anaesthetic and follow-up records of the patient. If nasal intubation is required, one should enquire about nostril patency (history of nasal polyps or deviated septum). Contraindications to the use of controlled hypotension, e.g. cerebrovascular, reno-vascular and moderate-to-severe coronary artery disease should also be assessed. Specific attention should be given to the needs of each class of patient.

\subsubsection{Oncology Patients}

Patients with head and neck cancer sometimes constitute the most challenging patients. Their upper airway may be seriously distorted, and they may have tracheal stenosis or hardening and fixation of the soft tissues due to radiotherapy.

In these patients, documents concerning previous surgeries, radiation and chemotherapy should be studied. The difficult airway may have been encountered, tracheostomy and residual tracheal stenosis, limited mouth opening, and neck extension may have been recorded [4].

Symptoms such as hoarse voice, stridor, and dyspnoea will indicate whether there is airway compromise due to stenosis, tumour, nerve damage or oedema. Post radiation, the patients may have tissue fibrosis with limited mouth opening or neck extension. Make a note of chemotherapy drugs, duration and interval since the last cycle of chemotherapy.

\subsubsection{Trauma Patients}

Trauma patients require a thorough history of the mechanism of injury, which would indicate intracerebral or spinal injury. Drug and/or alcohol ingestion is often a contributory factor, and $15 \%$ have other injuries. There is also potential for injuries to other organs and massive blood loss. Cervical spine injury occurs in $5-10 \%$ of patients with blunt trauma to the head and face. Therefore, the patient should be evaluated from 'head to toe' [5].

\subsubsection{Paediatric Patients}

Consider age, weight, prematurity, feeding, nutritional status and position during sleep. In patients with craniofacial abnormalities, look for associated syndromes such as Pierre Robin sequence or Treacher Collins syndrome as in addition to a difficult airway these patients may have involvement of other systems, such as cardiac, as a part of the syndrome, which will require specialist consultation [6].

\subsubsection{Toxic Airway/Infections}

Infection of dental and facial structures commonly leads to erythema and swelling of tissues. This can result in obstruction of airway and difficulty in airway management. Toxic airways (e.g. Ludwig's angina, dental cysts and osteomyelitis) with spreading infection often present as acute emergencies and may pose an extreme airway maintenance challenge. Direct laryngoscopy due to trismus, tissue distortion, oedema or abscess cavity and pus may not be possible and other means of securing the airway must be considered [4] (Fig. 7.1a, b).

\section{Examination Table 7.2}

\subsection{Airway Assessment}

A detailed airway assessment based on criteria in the ' $\mathrm{L}-\mathrm{E}$ M-O-N' method would help to stratify the risk of difficult intubation. The 'LEMON Law' can be used to quickly assess for potentially difficult airways [7]. A total score of 10 can be given as per the criteria and higher scores are associated with poor glottic visualization and difficult intubation.

Please refer the Fig. 2.2 on LEMON in Chap. 2 on preoperative evaluation and investigations.

In paediatric patients, the Mallampati score does not accurately predict a poor view of the glottis and there are no standard values for the thyromental and horizontal length of the mandible. Thus, an adaptation is required, and this is found in the 'COPUR SCALE' (Table 7.3) [7, 8].

Once the airway assessment is done, check

- Whether mask ventilation would be possible after induction of General Anaesthesia (GA).

- Anticipated view during direct laryngoscopy.

- Whether it would be possible to use a supraglottic airway as a rescue device.

- Possibility and accessibility of a surgical airway in case of a dire emergency. 
Fig. 7.1 (a) Buccal abscess (b) ludwigs angina
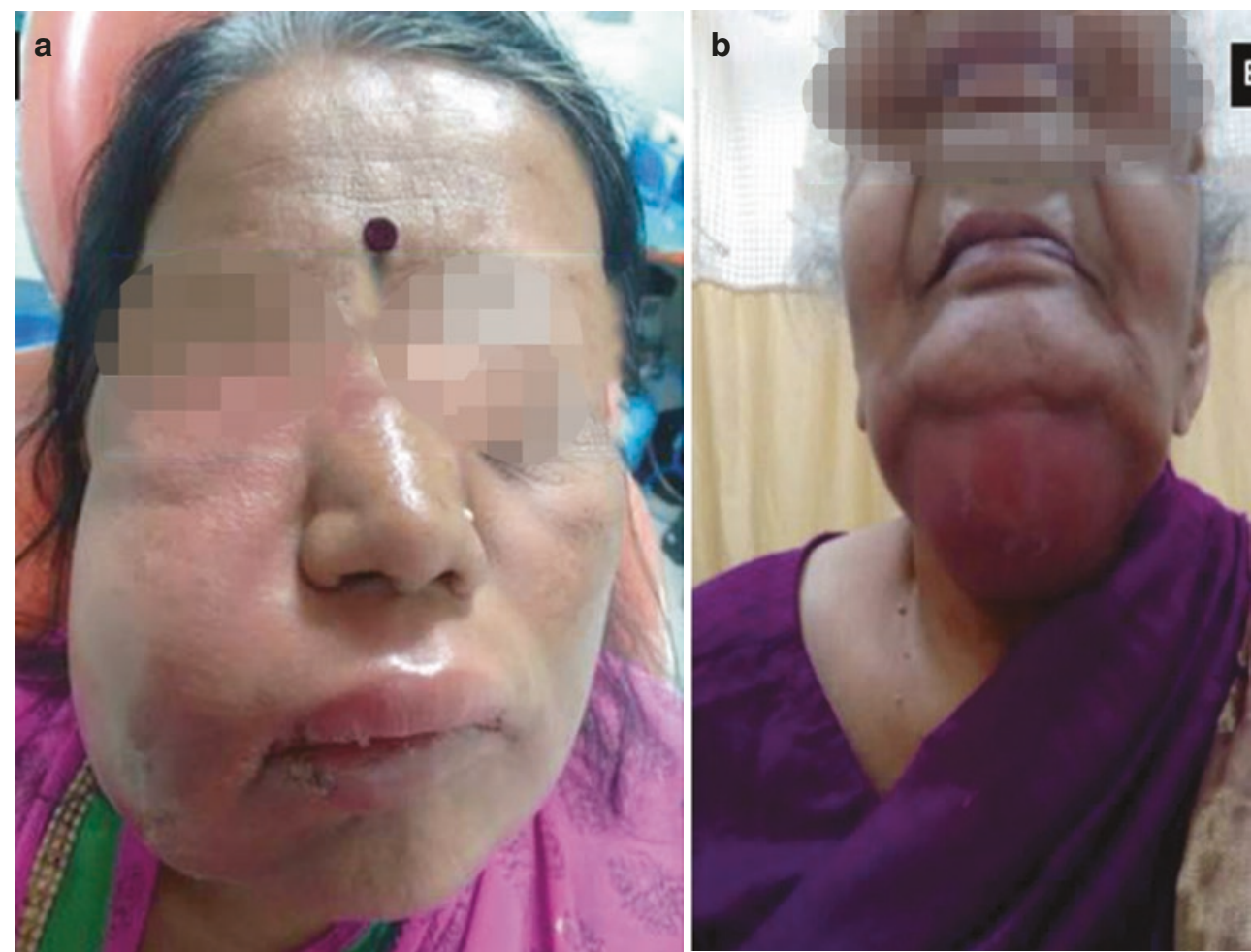

(C)Association of Oral and Maxillofacial Surgeons of India

Table 7.2 Checklist of things for a safe surgery

Pre-Anaesthesia Checklist
- Age and weight of the patient
- Type of maxillofacial surgery
- Previous surgeries/ associated complications
- Comorbidities and detailed medication list
- Cnown drug allergies
- Detailed airway examination
- Venous access
- Adequate blood and blood products

\subsection{General Physical Examination}

Look for pallor, icterus, cyanosis, clubbing, lymphadenopathy and oedema as well as the general nutritional status. Follow this up with pulse rate, blood pressure, respiratory rate, oxygen saturation, signs of dehydration, and responses denoted as AVPU-Alert, Verbal, Pain, Unresponsive.

AVPU is a simplified version of the Glasgow Coma Scale (GCS), which is easy to remember and apply to patients (Table 7.4) $[9,10]$. It consists of four possible stages. When recording AVPU, it is important to document the time the observation was taken and to track any changes over time as this will help monitor the progress of the patient (Table 7.4).

Apart from these, specific systemic examination, including cardiovascular, respiratory, per-abdomen and central ner- vous system, should be done and if in any doubt a specialist should be consulted.

There are various scales used to record a patient's level of consciousness. One of the most detailed is the GCS, which is used worldwide (Table 7.5) [9, 10]. The GCS is a reasonably complicated system, which, unless you use regularly, can be difficult to remember and apply correctly.

\subsubsection{Investigations}

In addition to routine blood tests like complete blood counts, kidney function tests, blood sugars, coagulation profile, serology, blood grouping and cross-matching is required for major surgery.

Chest X-ray helps in visualising any pathology in the lungs. It may also reveal tracheal deviation. X-ray soft-tissue neck, airway ultrasound, computerized tomography (CT), and magnetic resonance imaging (MRI) scans may be helpful in cancer, infections, abscesses or trauma cases.

For cancer surgery, a nasoendoscopy \& indirect laryngoscopy provides valuable information about the upper airway anatomy.

Electrocardiogram (ECG), echocardiogram, cardiopulmonary exercise testing or pulmonary function tests are required if there are symptoms or signs of cardiorespiratory disease. 
Table 7.3 Description of COPUR scale

\begin{tabular}{|c|c|}
\hline \multicolumn{2}{|l|}{ COPUR SCALE } \\
\hline$C=$ Chin & $\begin{array}{l}\text { Normal }-1 \\
\text { Small, moderately hypoplastic }-2 \\
\text { Markedly recessive }-3 \\
\text { Extremely hypoplastic }-4\end{array}$ \\
\hline $\begin{array}{l}O-\text { Opening } \\
\text { Interdental space between } \\
\text { front teeth }\end{array}$ & $\begin{array}{l}>40 \mathrm{~mm}-1 \\
20-40 \mathrm{~mm}-2 \\
10-20 \mathrm{~mm}-3 \\
<10 \mathrm{~mm}-4\end{array}$ \\
\hline $\begin{array}{l}P-\text { Previous intubation or } \\
\text { OSA }\end{array}$ & $\begin{array}{l}\text { Previous easy }-1 \\
\text { No attempt/no h/o OSA - } 2 \\
\text { OSA, previous difficult } \\
\text { intubation }-3 \\
\text { Extremely difficult intubation/ } \\
\text { tracheostomy/can't lie down } \\
\text { supine }-4\end{array}$ \\
\hline $\begin{array}{l}U-\text { Uvula } \\
\text { Mouth open tongue out }\end{array}$ & $\begin{array}{l}\text { Tip of uvula visible }-1 \\
\text { Uvula partially visible }-2 \\
\text { Uvula concealed/soft palate } \\
\text { visible }-3 \\
\text { Soft palate not visible }-4\end{array}$ \\
\hline $\begin{array}{l}R \text { - Range } \\
\text { Line from eye to orbit, range } \\
\text { of motion looking up \& down }\end{array}$ & $\begin{array}{l}>120^{\circ}-1 \\
60-120^{\circ}-2 \\
30-60^{\circ}-3 \\
<30^{\circ}-4\end{array}$ \\
\hline $\begin{array}{l}\text { Prediction points for ease of in } \\
\text { 5-7: Easy normal intubation } \\
\text { 8-10: Laryngeal help may be r } \\
\text { 12: More difficult, may be less } \\
\text { 14: Difficult intubation, fibre ol } \\
\text { be required } \\
\text { 16: Dangerous airway, conside } \\
\text { tracheostomy }\end{array}$ & $\begin{array}{l}\text { tubation } \\
\text { equired } \\
\text { traumatic } \\
\text { tic or other advanced technique may } \\
\text { awake intubation/potential }\end{array}$ \\
\hline
\end{tabular}

Table 7.4 AVPU scale described with examples

\begin{tabular}{|c|c|c|c|}
\hline & & Adult Behaviour & $\begin{array}{l}\text { Paediatric } \\
\text { Behaviour }\end{array}$ \\
\hline A & ALERT & $\begin{array}{l}\text { Eyes open } \\
\text { spontaneously. } \\
\text { Appears aware of and } \\
\text { responsive to the } \\
\text { environment. } \\
\text { Follows commands, } \\
\text { eyes track people and } \\
\text { objects }\end{array}$ & $\begin{array}{l}\text { Child is active and } \\
\text { responds } \\
\text { appropriately to } \\
\text { parents and other } \\
\text { external stimuli }\end{array}$ \\
\hline V & VOICE & $\begin{array}{l}\text { Eyes do not open } \\
\text { spontaneously but open } \\
\text { to verbal stimuli. } \\
\text { Able to respond in } \\
\text { some meaningful way } \\
\text { when spoken to }\end{array}$ & $\begin{array}{l}\text { Responds only } \\
\text { when his or her } \\
\text { name is called }\end{array}$ \\
\hline $\mathrm{P}$ & PAIN & $\begin{array}{l}\text { Does not respond to } \\
\text { questions but moves or } \\
\text { cries out in response to } \\
\text { painful stimuli such as } \\
\text { pinching the skin or } \\
\text { earlobe }\end{array}$ & $\begin{array}{l}\text { Responds only } \\
\text { when painful } \\
\text { stimuli are } \\
\text { received such as } \\
\text { pinching the nail } \\
\text { bed }\end{array}$ \\
\hline $\mathrm{U}$ & UNRESPONSIVE & $\begin{array}{l}\text { Patient does not } \\
\text { respond to any stimuli }\end{array}$ & No response at all \\
\hline
\end{tabular}

Table 7.5 Glasgow Coma Scale described in detail

\begin{tabular}{|l|l|l|}
\hline Glasgow Coma Scale & & \\
\hline Behaviour & Response & Score \\
\hline Eye opening (E) & Spontaneous & 4 \\
& To speech & 3 \\
& To pressure & 2 \\
& None & 1 \\
Verbal response (V) & Orientated & 5 \\
& Confused & 4 \\
& Words, but not coherent & 3 \\
& Sounds, but no words & 2 \\
& None & 1 \\
Motor response (M) & Obeys command & 6 \\
& Moves to localised pain & 5 \\
& Flexion withdrawal to pain & 4 \\
& Abnormal flexion (decorticate) & 3 \\
& Abnormal extension (Decerebrate) & 2 \\
Total score & No response & 1 \\
& Best response & 15 \\
& Comatose & $</=6$ \\
& Totally unresponsive & 3
\end{tabular}

\subsubsection{Counselling and Reassurance}

This is essential in all cases but especially so in patients who may have dramatic cosmetic changes or are undergoing cancer surgery like hemi-mandibulectomy. The possibility of tracheostomy and loss of voice must also be discussed with empathy. Video counselling may be resorted to in case of need.

\subsubsection{Informed Consent}

Any patient above the age of 18 years may give consent for surgery and anaesthesia. In the case of patients younger than 18 years, consent must be obtained from a parent or guardian after full explanation of procedures. The consent must be documented and signed by both the person taking the consent and the person giving the consent.

\subsubsection{Transport to Operation Theatre (OT)}

Should be with a trained health care worker especially if the patient has been given a sedative premedication. It is advisable for a parent or guardian to accompany younger children to the OT.

\subsubsection{Handover Documents}

All documents pertaining to the case must be handed over to the OT personnel and the handover documented. 


\subsection{Intraoperative Considerations}

7.5.1 Before Induction (Figs. 7.2, 7.3, 7.4, 7.5 7.6, 7.7, and 7.8) [6]

- Discuss the procedure and options with the lead surgeon

- Ensure patients vitals are stable

- Check anaesthetic machine and all equipment, including the 'Difficult Airway' cart and 'rescue devices' like Laryngeal Mask Airway (LMA) and tracheostomy tubes.

- If an 'uncommon' ETT like a flexometallic or (RAE) RingAdair-Elwyn tube is to be used, ensure that a regular tube of the appropriate size and one size smaller are available

- Ensure you have adequate help and each one knows what is expected of him/her

- Check intravenous (IV) access and all drugs available in the OT-drawn up and labelled.

- Check that blood is available if deemed necessary

- If intubation is difficult do not try more than 2-3 times with any one method (you will precipitate oedema and make matters worse)

- CALL FOR HELP EARLY

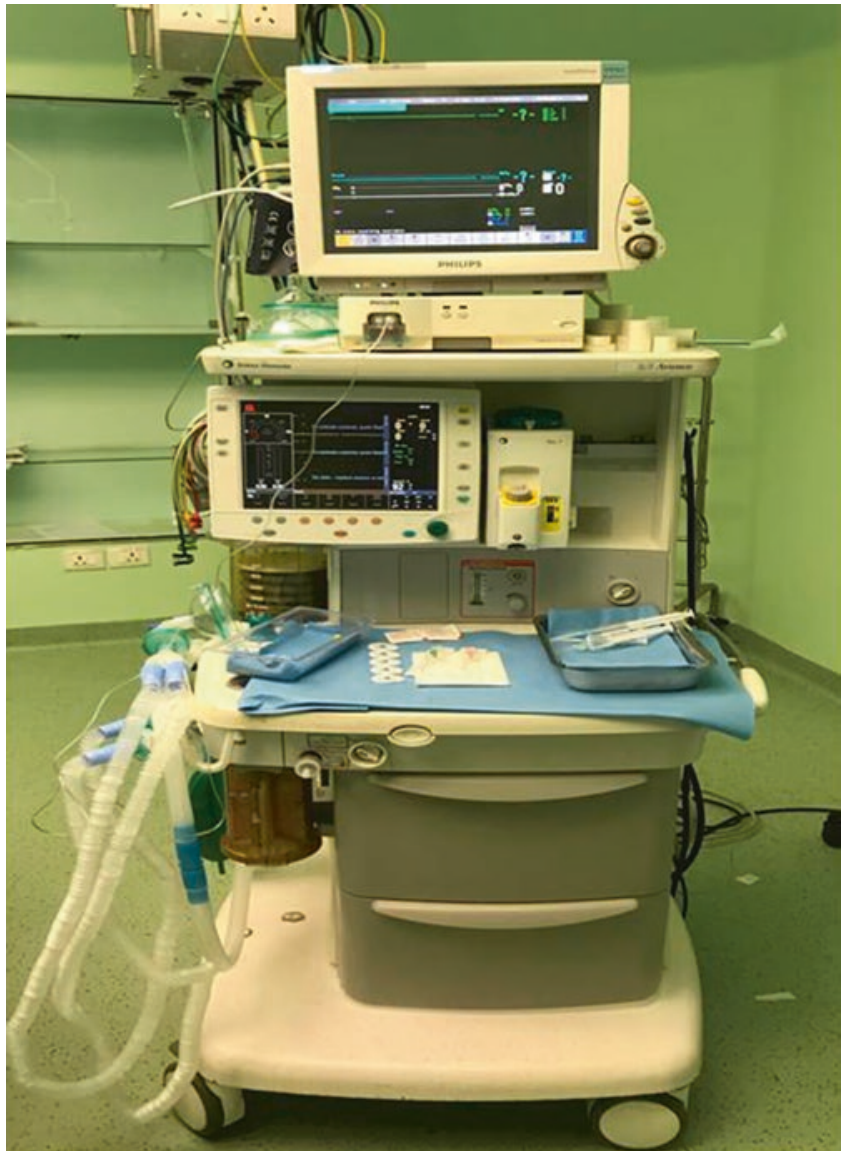

CAssociation of Oral and Maxillofacial Surgeons of India

Fig. 7.2 Anaesthetic apparatus
- Continue oxygenation with spontaneous respiration and wake up the patient if intubation is unsuccessful

More patients have died from lack of oxygen than from lack of an endotracheal tube!

Please see Chap. 42 in this book to read about avoidable human errors for a safer patient care. (A case of loss of airway is discussed in Chap. 42).

\subsubsection{Induction}

Anaesthesia may be induced either intravenously or with an inhalational agent. The choice of technique depends on:

- Airway factors: For example, an anticipated 'difficult airway' or limited mouth opening

- Patient factors:

Paediatrics

Post radiation

Trauma

- Associated comorbidities: e.g. ischemic heart disease or emphysema.

Nil-per-oral status

- Surgical factors:

Trauma

Cancer surgery

Cosmetic

Infective

Vascular malformation

\subsubsection{Monitoring}

In young patients belonging to ASA (American Society of Anesthesiologists) Grade I and II, standard monitoring will suffice. Invasive arterial blood pressure monitoring may be required if controlled hypotension is planned or if comorbidities warrant. Monitoring of temperature is required in children and those undergoing prolonged surgeries like corrective LeFort osteotomies. Urinary catheterization may be required during prolonged surgeries.

\subsubsection{Airway management: (Flow Chart 1)}

The method of securing the airway should be discussed with the surgeon. This depends on:

- Patient factors, such as age, obesity, pan-facial trauma or anticipated difficult airway

- Site of operation may require oral or nasal intubation with specially configured tubes.

- Anaesthetists'/surgeons' preferences. 


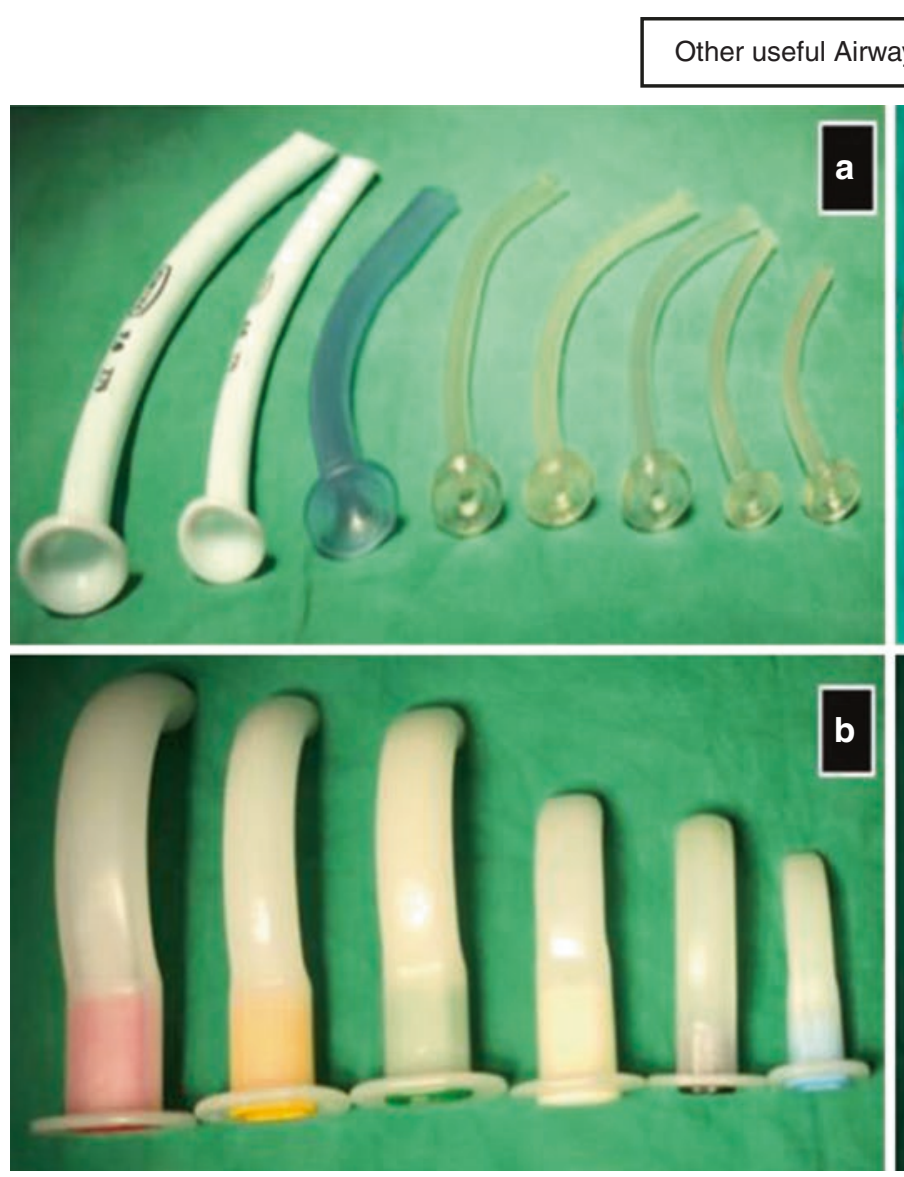

Other useful Airway Equipment

CAssociation of Oral and Maxillofacial Surgeons of India

Fig. 7.3 (a) Nasal airway, (b) Oral airway, (c) Ventilation mask and (d) Laryngoscope blades

Regular Endotracheal Tube
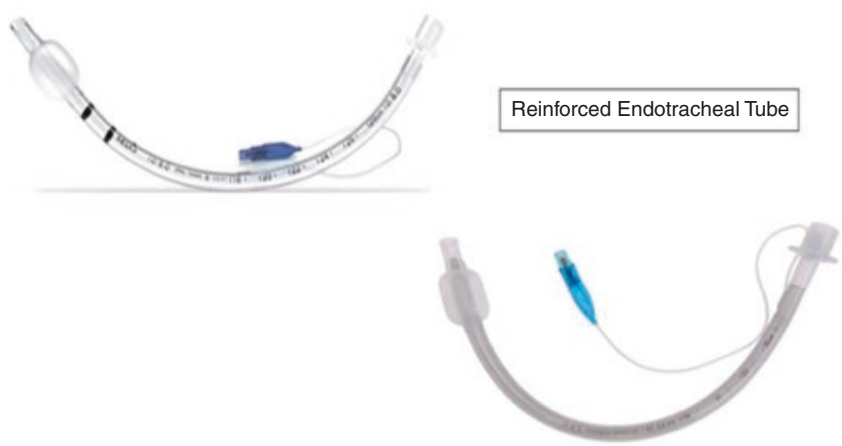

Fig. 7.4 Endotracheal tubes

Simple intraoral operations with no anticipated difficult airways can be done with standard nasal intubation or oral intubation under general anaesthesia with endotracheal tube pushed to the side opposite of surgery. Use of specially preformed tubes like RAE tubes and Reinforced/Armoured tube can be used to give good access to the surgical area (Figs. 7.4
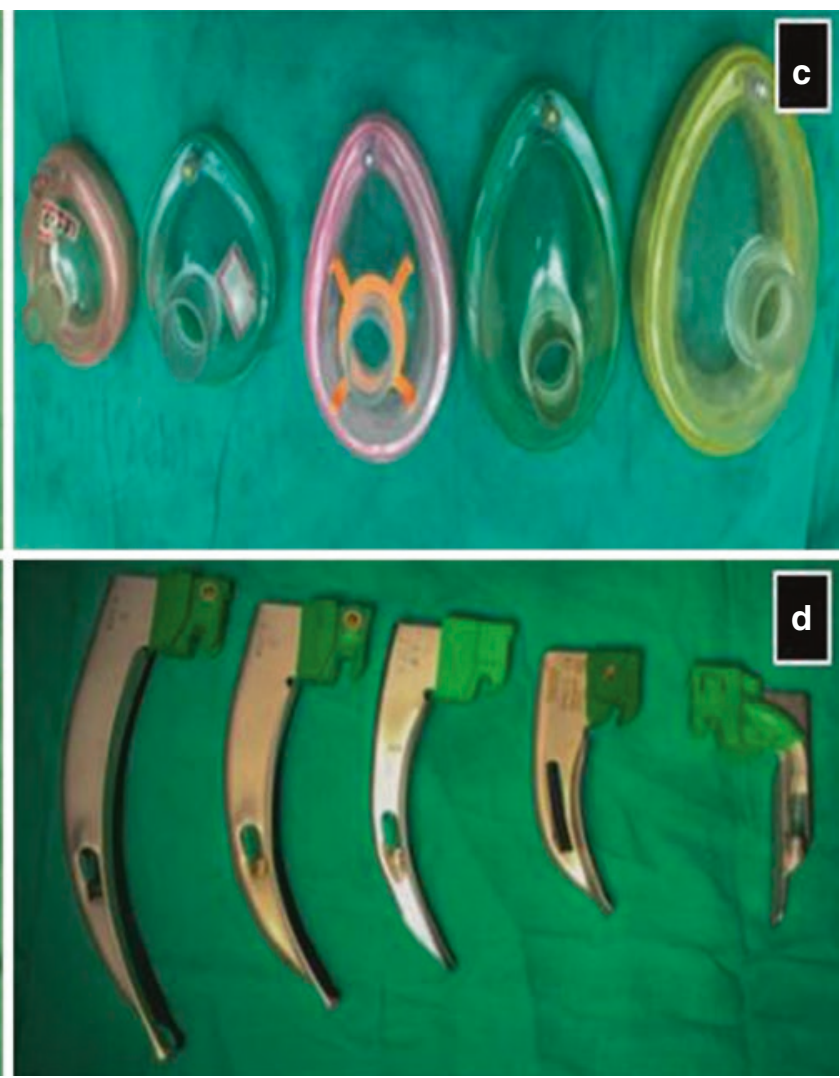

Special Endotracheal Tubes-RAE tubes

a

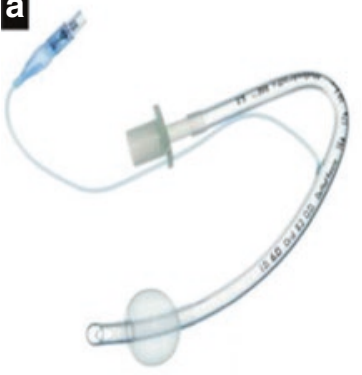

Fig. 7.5 RAE tubes

and 7.5). However, major corrective surgeries will require the oral cavity to be empty and hence warrant nasal intubation, submental intubation or a tracheostomy. Anticipated non-obstructed difficult airway as assessed by history and/or examination or suspected (cervical) $\mathrm{C}$-spine injury should be managed with awake fibre optic bronchoscopy or blind nasal 


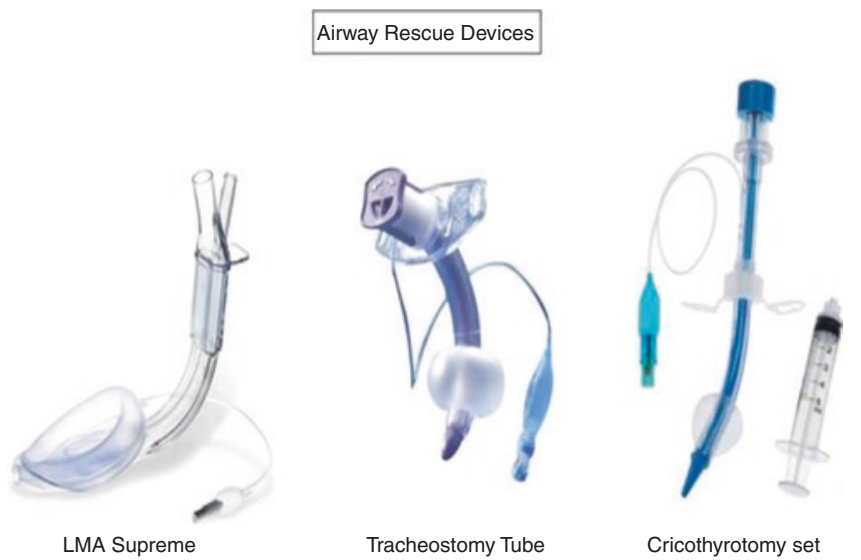

Fig. 7.6 Airway rescue devices

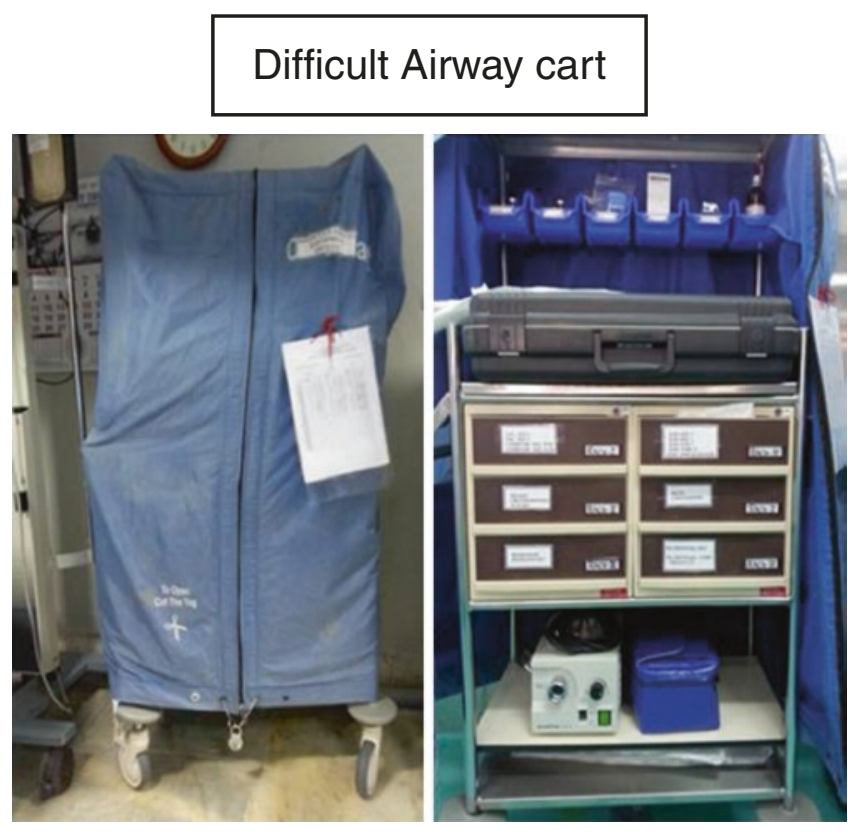

CAssociation of Oral and Maxillofacial Surgeons of India

Fig. 7.7 Difficult airway cart

intubation. The safety of awake intubation relies on the maintenance of spontaneous breathing, and the ability to stop and perform a different technique, such as awake tracheostomy, if intubation is unsuccessful. Most anaesthesiologists prefer the nasal route for fibre optic intubation, as it is technically easier. For this, the patency of the nostril should be assessed preoperatively, and roomier nostril should be chosen and prepared with vasoconstrictor drops like oxymetazoline hydrochloride.

Sedation may enhance the acceptability of awake fibre optic intubation. Dexmedetomidine infusion [11] serves this purpose very well. Airway instrumentation can be facilitated by local anaesthetic topicalisation of airway either by means of lignocaine nebulisation or 'spray as you

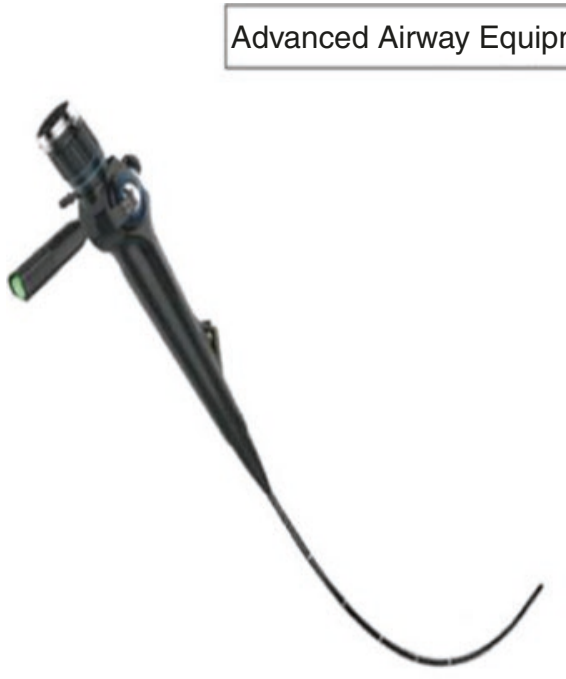

Fiberoptic Scope

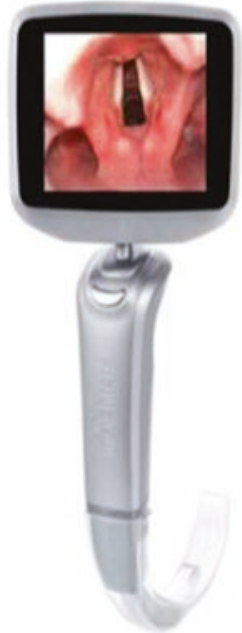

Video Laryngoscope

Fig. 7.8 Advanced airway equipment

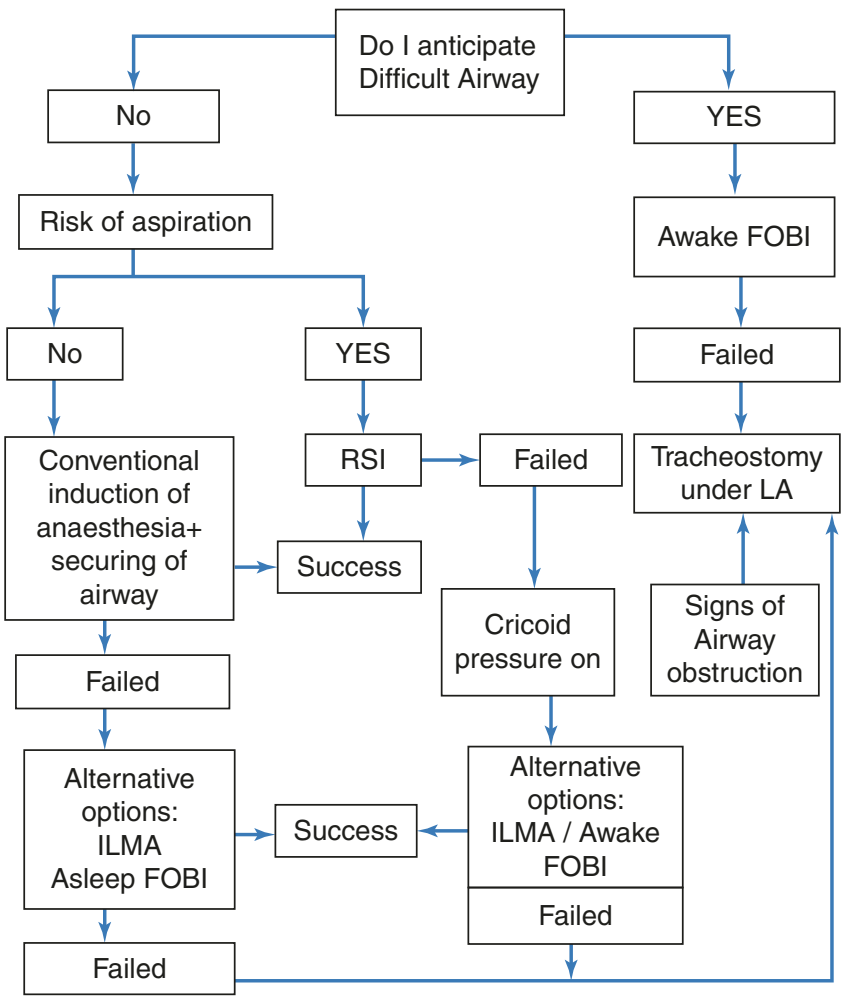

Flow Chart 1 Airway management in oro-maxillo-facial surgery

go' technique and/airway blocks (glossopharyngeal, superior laryngeal and recurrent laryngeal nerve blocks) [12]. An antisialogoguelike glycopyrrolate administered $30-45$ min prior will reduce the secretions and will facili- 

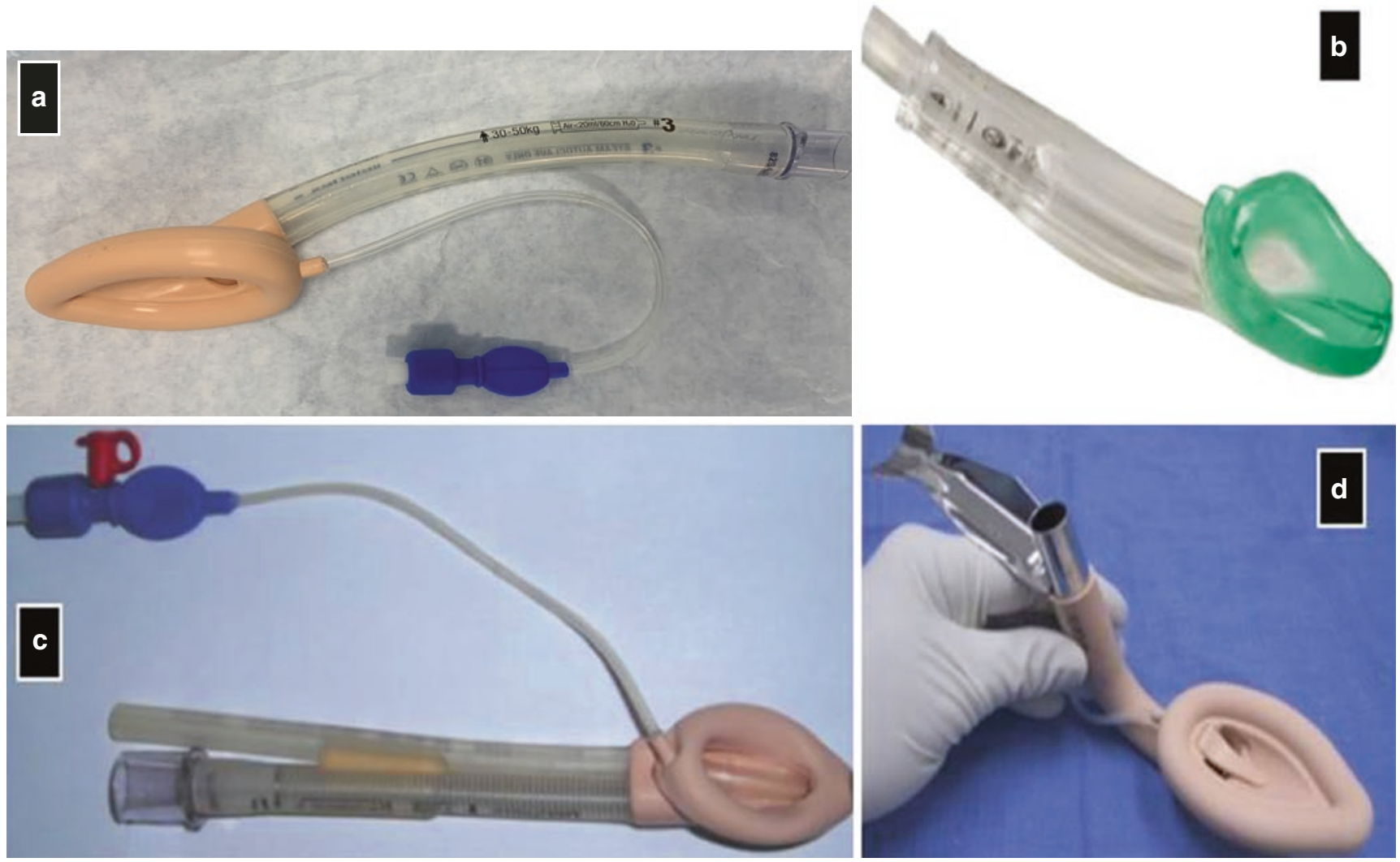

CAssociation of Oral and Maxillofacial Surgeons of India

Fig. 7.9 (a,b,c,d) Supraglottic airways

tate awake fibre optic intubation. Airway blocks may not be an option to facilitate awake intubation in cases such as extensive pan-facial fractures or post-radiation fibrosis of the neck. Fibre optic intubation may be impractical in case of oro-maxillofacial trauma if associated with severe airway bleeding that can obscure visibility and other options such as tracheostomy under local anaesthesia (LA) should be considered.

The traditional 'blind nasal intubation' is rarely employed these days but may be used if a fibre optic scope is not available or not possible (Video 7.1).

A 'plan B' should always be present if intubation by one method is unsuccessful.

During long surgery and if ventilated in the post-operative period, the Endotracheal (or tracheostomy) cuff pressure should be measured using an aneroid manometer. A pressure of $20-30 \mathrm{~cm}$ of $\mathrm{H}_{2} \mathrm{O}$ is considered as standard in adults.

In supraglottic obstruction-associated with stridor and respiratory distress, as in case of upper airway trauma, rapidly expanding infections like epiglottitis, Ludwig's angina, etc. awake fibre optic bronchoscopy and intubation may not be the right choice. In such a situation, an awake tracheostomy under local anaesthesia must be considered.

\subsubsection{Supraglottic Airway Devices}

Several varieties of supraglottic airway devices are available (Fig. 7.9). However, these are not ideal devices for oromaxillofacial surgeries requiring the oral cavity to be empty, but can be lifesaving as rescue devices in 'cannot ventilate, cannot intubate' situations to ventilate a patient until the definitive airway is secured. However, a flexible reinforced LMA can be used for simple dental extractions and nasal, zygomatic and superficial facial surgery. However, obstruction and dislodgement can occur, especially when the mandible is moved.

\subsection{Special Considerations}

Paediatrics: [6] Children will not co-operate for awake fibre optic intubation. Hence, in such cases, the airway can be secured after inhalational induction without relaxation after establishing IV access. A nasopharyngeal airway may be passed gently into one nostril and connected to a breathing circuit while monitoring the end-tidal carbon dioxide $\left(\mathrm{EtCO}_{2}\right)$ and continuing the anaesthetic and oxygenation via 
the airway. The other nostril may now be prepared with a vasoconstrictor and local anaesthetic and used for fibre optic intubation (Fig. 7.10).

\subsubsection{Retromolar and Submental Intubation}

These techniques were developed as alternatives to tracheostomy in maxillofacial surgeries requiring intra-operative inter-dental fixation for malocclusion correction like comminuted fracture of the mid-face or the nose, where nasal intubation is contraindicated.

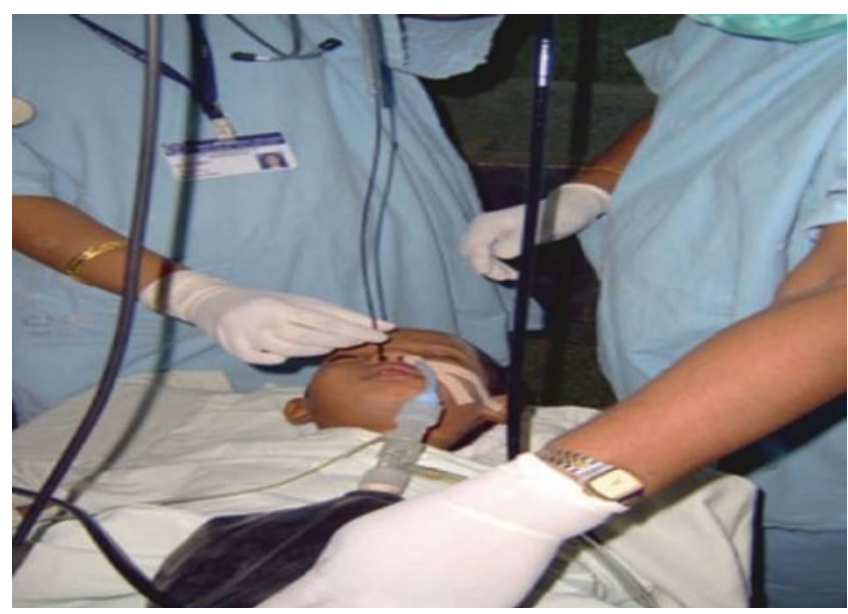

CAssociation of Oral and Maxillofacial Surgeons of India

Fig. 7.10 Fibre optic intubation in children

\subsubsection{Retromolar Intubation}

Pre-operatively check the adequacy of the retromolar space. This is done to prevent kinking of the endotracheal tube in retromolar space by insinuating the index finger behind the third molar and asking the patient to clench his teeth. The patients' airway is then intubated by the conventional method and the ETT is pushed in the retromolar space and brought out from the angle of the mouth and connected to the ventilator. The spiral reinforced/armoured ETT is preferred as it is kink resistant (Fig. 7.11).

\subsubsection{Submental Orotracheal Intubation: [13]}

(Fig. 7.12a-f)

(See additional reading material on submental intubation given at the end of the chapter).

Just like retromolar intubation, it also requires the use of a spiral reinforced/armoured ETT in order to prevent the tube from kinking during its usage. Following conventional orotracheal intubation, a $2-\mathrm{cm}$ incision is made lateral to the midline between the chin and the angle of the mandible and an opening is made in the floor of the mouth by the surgeon, avoiding the submandibular salivary glands. The machine end of the ETT without the connector is pulled through the tunnel, using gentle rotational movements. Following this manoeuvre, the tube is connected to the ventilating machine and sutures are used to fix the tube in position. If the procedure of disconnecting the ETT is long and pulling it out is prolonged, there is a possibility of hypoxia. So monitor oximetry closely and use high oxygen concentrations immediately before and after the placement of the submental tube (Video 7.2).

Fig. 7.11 Retromolar intubation

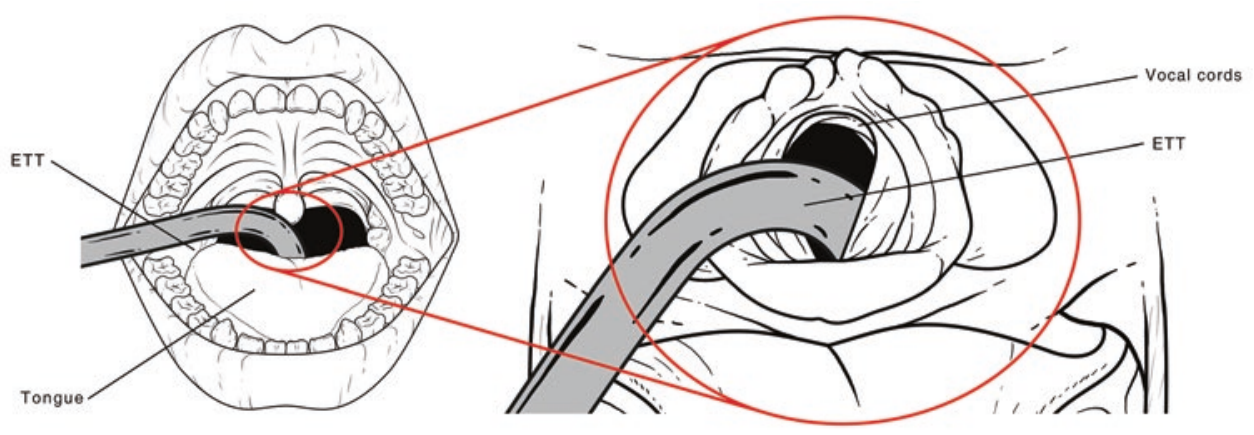

(C)Association of Oral and Maxillofacial Surgeons of India 

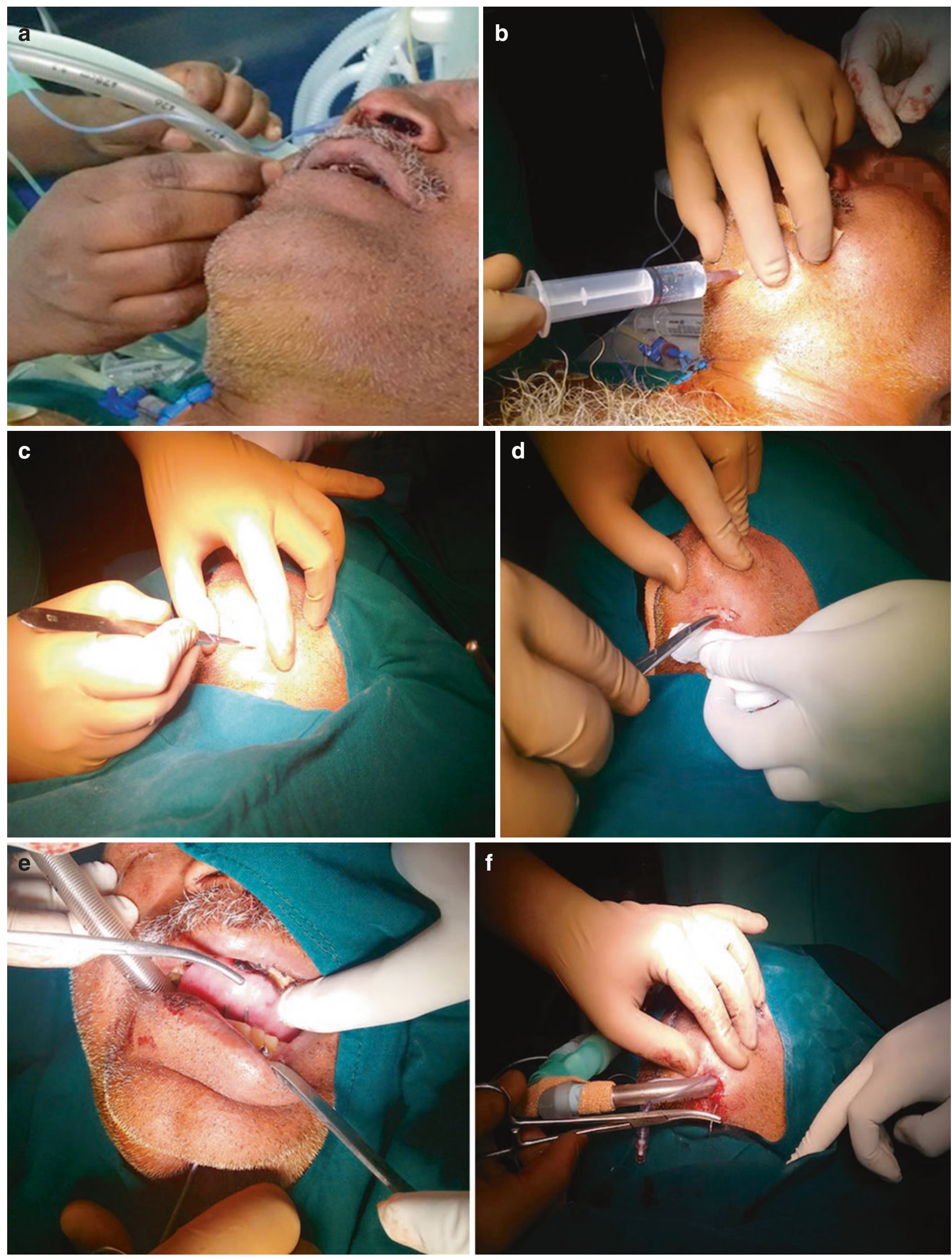

(CAssociation of Oral and Maxillofacial Surgeons of India

Fig. $7.12(\mathbf{a}-\mathbf{f})$ Various steps in submental intubation 


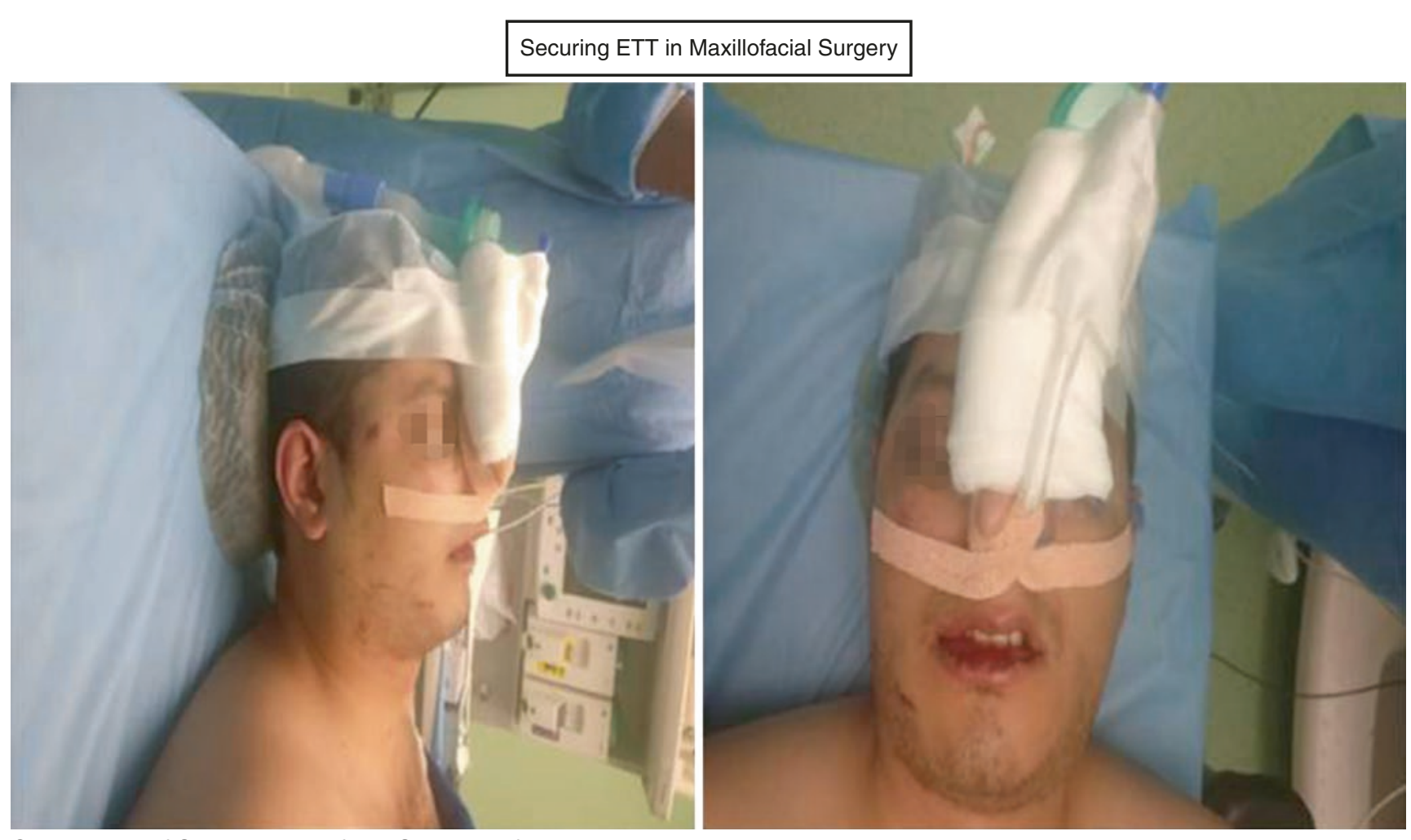

CAssociation of Oral and Maxillofacial Surgeons of India

Fig. 7.13 Securing ETT in maxillofacial surgery

\section{Securing the Endotracheal Tube}

The ETT may dislodge intra-operatively as the airway is shared between the surgeon and anaesthetist; hence, special attention should be paid to securing the ETT. Preformed nasal RAE tubes, if used, should be supported on the nasal bridge and forehead with the help of preformed supports or pads and secured on the forehead with tapes in addition to securing at the nostril (Fig. 7.13). Submental tubes can be secured with sutures (Fig. 7.14) South Pole oral RAE tubes are usually fixed in the middle of the lower jaw with tapes (Fig. 7.15).

\subsubsection{Eyes}

Preferably taped with transparent dressing or specialized eye pads to capture moisture and prevent drying especially during prolonged surgeries (Fig. 7.15).

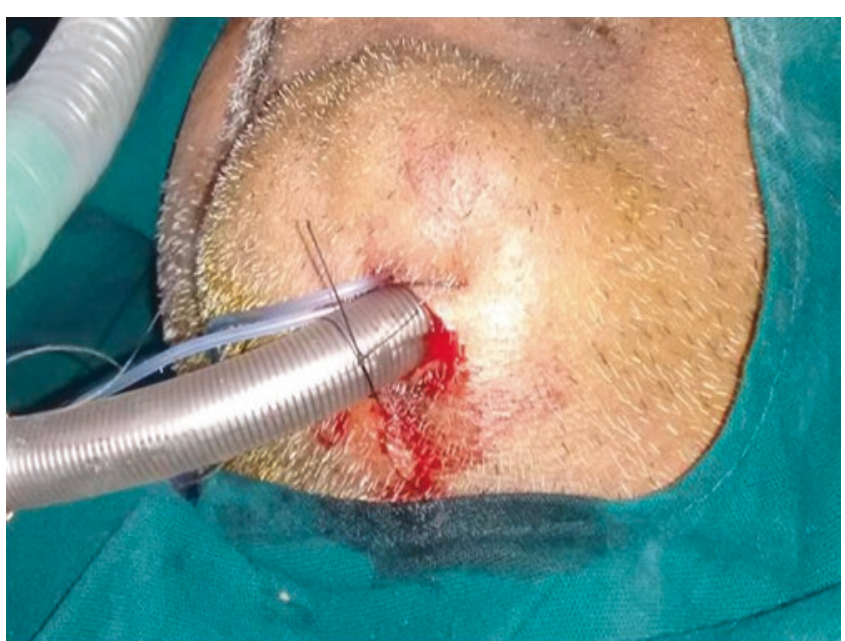

(C)Association of Oral and Maxillofacial Surgeons of India

Fig. 7.14 Securing submental tube with sutures 


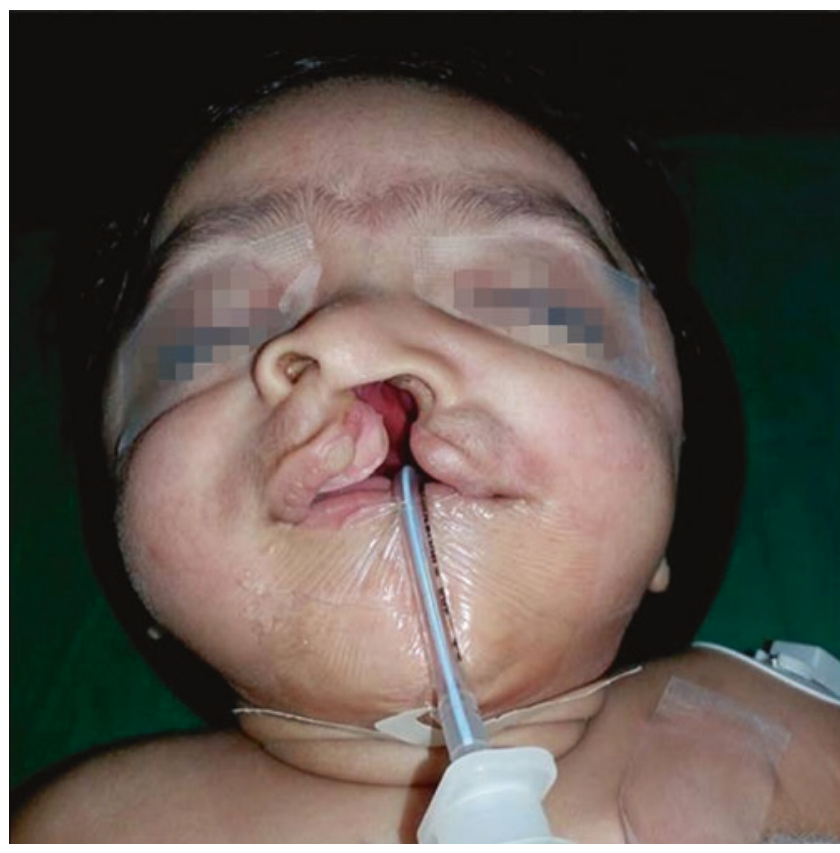

CAssociation of Oral and Maxillofacial Surgeons of India

Fig. 7.15 Securing oral south pole tubes/protection of the eyes with tapes

\subsubsection{Positioning}

Reverse Trendelenburg (anti-gravity) position with shoulder roll for adequate surgical exposure is preferred. Further, the operation table may be turned away from the anaesthetist and the anaesthesia machine by $90^{\circ}$ or $180^{\circ}$. Hence, long breathing circuits, IV extensions and long cables for monitoring will be required.

\subsubsection{Throat Pack}

Saline-soaked throat packs will be required to protect the airway from blood, debris and saliva. It is advised to fix the tail end of the throat pack to the oral endotracheal tube whenever feasible to prevent accidental leaving behind of the throat pack at the end of surgery. Time of insertion and removal of the throat pack should be documented and carefully checked before extubation. If interdental wiring is planned at the end of surgery, then prior to doing so all throat packs should be removed and gauze counts should be confirmed.

\subsection{Maintenance of Anaesthesia}

Once the airway is secured, anaesthesia can be maintained with total intravenous anaesthesia (TIVA) or with volatile anaesthetics or combination of both as described earlier. Controlled ventilation with an intermediate-acting muscle relaxant such as atracurium or vecuronium is used.
Intra-operative analgesia is preferably provided with short-acting opioids such as fentanyl. Dexamethasone can be administered intra-operatively to reduce post-operative swelling, for its analgesic properties and as a prophylactic against post-operative nausea and vomiting (PONV) [14]. Orthognathic surgeries are associated with a high incidence of PONV; hence, additional antiemetics such as ondansetron should be administered prior to extubation especially if interdental wires are planned. Hypothermia can be a potential complication of prolonged orthognathic surgeries. Hence, temperature should be monitored and warming measures like intra-operative warm I.V fluids, forced air mattresses should be used. If there is a fear of airway compromise postextubation, a tracheostomy should be done electively.

\subsubsection{Deep Vein Thrombosis (DVT) Prophylaxis}

Cancer patients and patients undergoing long surgery are at risk of developing thromboembolic complications. One or more of the following methods may be used to reduce its incidence.

Mechanical-Thromboembolic deterrent/Compression stockings (TEDS), pneumatic calf compression boots.

Pharmacological—Low-molecular-weight heparin such as Clexane could be used in patients at high risk for venous thromboembolism (VTE).

\subsubsection{Control of Bleeding}

The head and neck region receives rich blood supply from the branches of the carotid artery, and hence there is a tendency to bleed profusely during maxillofacial surgeries. Major bleeding can occur from branches of the maxillary artery or from pterygoid venous plexuses, leading to significant blood loss, warranting blood transfusion. Further, some of these procedures especially corrective osteotomies are extensive and time consuming. Surgical haemostasis is hampered by limited access. Risks involved in allogeneic blood transfusion have also been well documented and hence it is important to institute measures to reduce intra-operative blood loss and blood transfusion.

Methods to control intra-operative blood loss include:

Reverse Trendelenburg (anti-gravity) positioning.

Ensuring adequate venous drainage.

Antifibrinolytics, e.g. Tranexamic acid.

Infiltration of the tissues with vasoconstrictors like adrenaline.

Controlled hypotension.

Intermittent positive pressure ventilation and maintenance of mild hypocarbia. 
1\&2. Positioning and venous drainage: Reverse Trendelenburg (anti-gravity) positioning by $30^{\circ}$ is recommended as it decreases bleeding by causing mild postural hypotension. Neck should be preferably positioned in the neutral position or turned slightly towards the surgeon. Extreme flexion or rotation of the neck to one side should be avoided to prevent venous engorgement. A minimum of 2-finger breadth space is recommended between chin and chest if flexion of neck is required.

3. Antifibrinolytics: A number of clinical trials have shown that the use of antifibrinolytics like tranexamic acid (TXA) reduces the peri-operative blood loss and the need for blood transfusion significantly. In 2011 World Health Organization added tranexamic acid (TXA) to its list of essential drugs [15]. The European guidelines on management of major bleeding and coagulopathy following trauma suggests a $1 \mathrm{~A}$ recommendation for the use of TXA in the case of traumatic and perioperative bleeding [16]. Dose reduction is required in renal impairment. Also, caution should be exercised while administering to patients with history of seizures.

4. Infiltration of the tissues with lignocaine + adrenaline: Usually the surgeons infiltrate the tissues with lignocaine, a local anaesthetic (LA), and adrenaline, a vasoconstrictor, prior to incision so as to reduce bleeding. Before doing so, the maximum allowable dose of local anaesthetic and adrenaline must be calculated and not exceeded to avoid toxicity and arrhythmias. A dilution of 1:200000 adrenaline is considered safe. If a local anaesthetic drug has been used for securing the airway, the dose of LA used must be considered in total calculation. ECG should always be monitored during and after infiltration.

5. Controlled hypotension: is defined as iatrogenic reversible reduction of the patients mean arterial blood pressure. Controlled hypotension can be achieved either by decreasing peripheral vascular resistance and/or cardiac output [17]. However, hypotension induced by decreasing cardiac output may not be ideal as it decreases tissue perfusion. A reduction by $30 \%$ from the baseline mean arterial pressure (MAP) level is generally considered to be safe. But it may be unsafe in some patients such as those with chronic kidney disease, ischemic heart disease and carotid artery disease [17]. Therefore, their suitability for controlled hypotension should be assessed and recorded during the pre-anaesthetic workup.

Over the years, several protocols have been developed. The main strategies are

- Standard anaesthesia with non-pharmacological measures.

- Deep anaesthesia with analgesia.

- Standard anaesthesia with hypotensive drugs.
Standard anaesthesia with Non-pharmacological measures: This relies on

- Optimal anti-Trendelenburg positioning to achieve postural hypotension.

- Intermittent positive pressure ventilation with mild hypocarbia.

Pharmacological measures: It relies on drugs used to either deepen the plane of anaesthesia and/or produce vasodilatation.

The ideal drug used for controlled hypotension should be easy to administer, quick in onset and recovery with predictable effect, no toxic metabolites and should preserve organ perfusion [17]. At present, no such drug is available and hence a combination of drugs is often used.

Deep anaesthesia can be achieved either with volatile anaesthetics or with intravenous agents.

Most volatile anaesthetic agents are potent vasodilators. This property can be exploited to reduce blood pressure. However, when used alone, the minimum alveolar concentration (MAC) values required to achieve this are high and can result in hepatic and renal injury and also delay awakening. They are therefore used at lower concentrations with other pharmacological agents. Most commonly used volatile agents include isoflurane, sevoflurane and desflurane. Halothane is preferably avoided due to its arrhythmogenic potential with adrenaline.

Propofol Infusions: This has been extensively used in neuro anaesthesia for controlled hypotension as part of total intravenous anaesthesia (TIVA). It can be used either as part of TIVA or combined with volatile anaesthetics.

Opioids: Opioids decrease the doses of agents required to produce anaesthesia and hypotension by decreasing pain. Most commonly used short-acting opioids include fentanyl and remifentanil.

\subsubsection{Hypotensive Drugs: (Appendix II)}

Hypotension should be carried out only to that level needed to reduce bleeding and only for that time of the surgery where it is of benefit in reducing significant blood loss. A number of drugs have been tried either alone or in combination to reduce blood pressure. While using them, one needs to be aware of their potential complications and contraindications. Drugs commonly used are beta-blockers, glyceryl trinitrate and sodium nitroprusside. Newer drugs like dexmedetomidine along with a propofol/remifentanil combination are gaining popularity [18, 19].

Invasive arterial blood pressure monitoring is recommended if infusions of hypotensive drugs are used for controlled hypotension. Intra-op serial monitoring of $\mathrm{ABG}$ (arterial blood gases), acid-base balance and lactate levels 
Table 7.6 Potential complications in specific maxillofacial procedures

\begin{tabular}{|c|c|c|c|}
\hline Complications & Surgery & Pathogenesis & Management \\
\hline Bradycardia [21] & $\begin{array}{l}\text { Levering of zygomatic } \\
\text { fractures. } \\
\text { Manipulation of } \\
\text { midface }\end{array}$ & Oculocardiac reflex & $\begin{array}{l}\text { 1. Cessation of stimulus. } \\
\text { 2. Anticholinergics: Atropine/ } \\
\text { glycopyrrolate }\end{array}$ \\
\hline $\begin{array}{l}\text { Intra-operative bleeding: } \\
\text { Occurs due to high vascularity of the area not } \\
\text { amenable to cauterization. }\end{array}$ & $\begin{array}{l}\text { Maxillary osteotomies. } \\
\text { LeFort-I osteotomies }\end{array}$ & $\begin{array}{l}\text { Bleeding from Pterygoid venous } \\
\text { plexuses. } \\
\text { Sphenopalatine artery } \\
\text { Descending palatine artery } \\
\text { Internal maxillary artery }\end{array}$ & $\begin{array}{l}\text { 1. Large bore I.V. cannula. } \\
\text { 2. Intraoperative tranexamic } \\
\text { acid. } \\
\text { 3. Controlled hypotension. } \\
\text { 4. Autologous blood donation. } \\
\text { 5. Blood transfusion may be } \\
\text { needed. }\end{array}$ \\
\hline Tracheal tube damage & $\begin{array}{l}\text { Lateral nasal } \\
\text { osteotomies [20] } \\
\text { Le fort surgeries }\end{array}$ & $\begin{array}{l}\text { Direct damage. } \\
\text { Bubbling of gas from the nose- } \\
\text { Anaesthesia circuit leak with } \\
\text { inability to ventilate. }\end{array}$ & $\begin{array}{l}\text { 1. Immediate tube change. } \\
\text { 2. Laryngeal packing may be } \\
\text { attempted. } \\
\text { 3. Precautions - Careful } \\
\text { surgery } \\
\text { 4. Unilateral: Intubate via } \\
\text { contralateral nare. }\end{array}$ \\
\hline \multicolumn{4}{|l|}{ Wiring of tracheal tube to maxilla } \\
\hline $\begin{array}{l}\text { Wide haemodynamic swings - } \\
\text { Bradyarrythmias/ asystole }\end{array}$ & $\begin{array}{l}\text { Radical neck } \\
\text { dissections }\end{array}$ & $\begin{array}{l}\text { Carotid sinus stimulation/ stellate } \\
\text { ganglion stimulation. }\end{array}$ & $\begin{array}{l}\text { 1. Cessation of stimulus } \\
\text { 2. Carotid sinus block with LA } \\
\text { 3. Stellate ganglion block. } \\
\text { 4. Vagolysis. }\end{array}$ \\
\hline
\end{tabular}

with hourly urine-output measurement should help to prevent organ dysfunction.

Isovolaemic haemodilution was once considered an adjunct in orthognathic surgeries to induce hypotension to reduce blood transfusion. It has become less common these days. The technique involves preoperative blood donation with IV fluids replacement of circulating volume followed by autologous whole blood transfusion as needed in the intra- or post-operative period.

Intra-op Analgesia can be achieved with NSAIDs, Paracetamol, opioids, intraoral LA infiltration and by mandibular or maxillary nerve blocks performed intra-op by the surgeon.

Intra-operative complications: The anaesthetist must be aware of and prepared for potential intra-operative complications [20, 21] (Table 7.6).

\subsubsection{Elective Tracheostomy}

Indications for elective tracheostomy are:

- Airway obstruction above the glottis - consider tracheostomy under LA.

- After extubation, Known or anticipated presence of an obstructed airway.

- Other general conditions requiring tracheostomy:

- Certain head injuries

- Massive chest injuries

- Incidental pre-existing disease

Inadequate postoperative nursing care.

\subsection{Post-Operative}

Emergence and extubation [22] Flow Chart 2-AIDAA (All India Difficult Airway Association) Guidelines for the management of anticipated difficult extubation and Table 7.7.

(flow chart 2 re-used with permission from IJA and AIDAA)

- After discussion with the surgeon, the decision of extubation post-surgery should be taken on a case-by-case basis.

- Before completion of the surgery, the induced hypotension should be ceased and time should be given to the surgeon to check for haemostasis. To check haemostasis, few surgeons prefer to increase mean blood pressure by 20-30\% above pre-op level.

- At the end of the surgery, throat packs should be removed and clots or debris should be suctioned from the oropharynx.

- Prior to extubation cuff leak test may be performed to check for no airway oedema.

- A smooth emergence and extubation with less coughing and bucking is desirable. With the risk of the possibility of ongoing bleeding in the upper airway it is usual for patients to be extubated awake. Confirm that the patient is awake and breathing spontaneously.

- The Endotracheal tube should be left in situ, until the patient is fully conscious when the jaws are wired together, or any other airway obstruction is anticipated. Two types of maxillomandibular fixation (MMF) are available: Rigid MMF with jaw wiring, i.e. patients would be extubated with no ability to open their mouths and 
Table 7.7 Guidelines for extubation

\begin{tabular}{|c|c|}
\hline Decision based & Individual case \\
\hline & AIDAA guidelines Flow Chart 2 \\
\hline & Cuff leak test \\
\hline & Jaws wired - awake extubation \\
\hline & $\begin{array}{l}\text { Jaws not immobilized }>\text { Guedel airway/ } \\
\text { nasopharyngeal airway }\end{array}$ \\
\hline Stop & Induced hypotension \\
\hline Keep ready & Difficult airway cart \\
\hline & Appropriate anaesthetic drug drawn up \\
\hline & Surgical team for tracheostomy \\
\hline & Post op ICU bed \\
\hline Avoid & Tight face mask ventilation \\
\hline
\end{tabular}

MMF with elastics often applied, albeit later (from hours to 1 or 2 days) into the recovery phase where mouth opening will not be a problem.

- Guedel's airway or nasopharyngeal tube should be used to maintain the airway if jaws are not immobilized. A nasopharyngeal tube provides an extra dimension of safety in recovery.

- Nasal Endotracheal tubes removal should be gentle. To avoid passing of fresh tube through the vulnerable nasal mucosa, the ETT can be withdrawn into and left in oropharynx to serve as a nasopharyngeal airway. Submental ETT should be removed back from the oral cavity and closure of the submental incision done before the extubation.

- Consider extubation over a tube changer in case of difficult intubation or surgery.

- Avoid applying tight facemask to protect surgical correction after extubation.

- For reintubation, airway equipment / difficult airway chart should be available on standby and in case of failed extubation appropriate anaesthetic drugs drawn up in the required doses.

- In case of MMF, wire cutters or scissors should be available immediately for release of elastics band fixation.

- Until successful extubation and stabilization of patient, the surgical team should remain in the operating theatre.

- Before transfer to recovery, a short period of observation in the theatre should be followed.

- Handover and transfer to recovery should be done by the anaesthetist.

- Careful documentation of surgery details, vital signs, status at transfer, blood loss and replacement, drugs given, analgesia planned and expected problems should be done.

\subsubsection{Handover from OT to Recovery Room/ICU}

\section{Clinical Criteria for Shifting:}

- Patient should be awake and moving all 4 limbs

- Respiration should be regular with adequate depth

- Stable vital parameters

- $\mathrm{SpO} 2>95 \%$ on room air

- Pulse rate optimum for age

- Respiratory rate $<30 /$ min

- Normothermic

- No active bleeding from surgical site

Anaesthesiologist should accompany patient to recovery

- Give handover to responsible personnel

- Handover should include

- Name and age of patient

- Surgery done

- Any positive history and examination

- Type of anaesthesia and drugs (time and dose) given, including analgesics.

- Any intraoperative event

- Clear postoperative orders

- Complete anaesthesia form and sign and name

- Nursing in the postoperative period should be in the reverse Trendelenburg position to decrease oedema and bleeding.

- In cases of Le Fort II and III fractures, one should be aware that the degree of oedema could worsen in the first $48 \mathrm{~h}$.

- For close observation, some patients need to be admitted to a high dependency unit. Patients sent to ICU are those who remain intubated or ventilated.

In case of inadequate postoperative care facilities like an ICU, the patient may be required to be sent to another hospital (see appendix III and 1V).

\subsection{Post-Operative Complications and Management}

- Immediate

- Airway Problems

- Postoperative bleeding and haematoma

- Delayed

- Nausea and Vomiting

- Post-operative pain 


\section{AIDAA 2016 Guidelines for the Management of Anticipated Difficult Extubation}

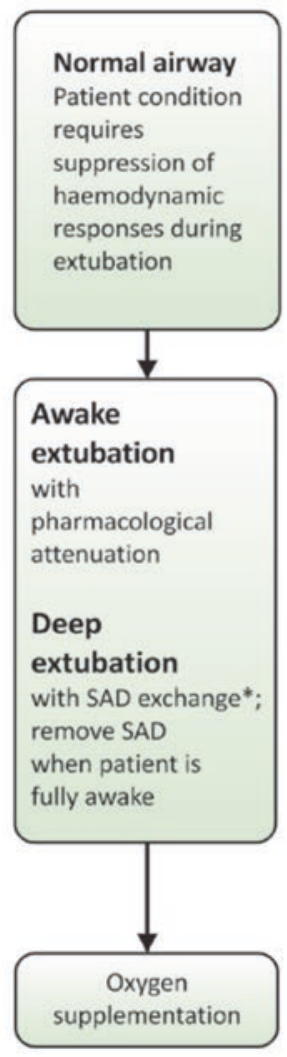

This flow chart should be used in conjunction with the text

* Exchange should be performed only if the patient did not have difficult mask ventilation, difficult intubation and is not a case of full stomach (obese, pregnant, recent ingestion of food or raised intra-abdominal pressure)

** Suspected nerve damage/structural damage to airway

AEC = Airway exchange catheter

CPAP $=$ Continuous positive airway pressure

ETT = Endotracheal tube

FOB $=$ Fibreoptic bronchoscope

HDU $=$ High dependency unit

HFNC $=$ High flow nasal cannula

ICU $=$ Intensive care unit

$\mathrm{O}_{\text {, }}=$ Oxygen

OT $=$ Operation theatre

$S A D=$ Supraglottic airway device

$\mathrm{VTe}=$ Expired tidal volume
After AEC/FOB removal,

continue oxygen

supplementation

Recruitment of lung through ETT during extubation.
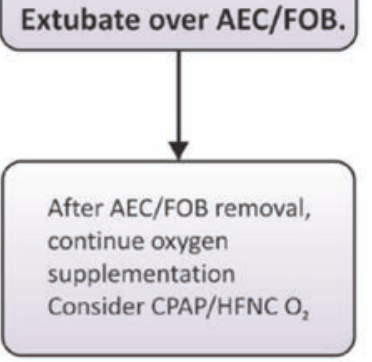

\section{Ds}

Difficult mask ventilation

Difficult intubation/reintubation

Difficulty because of pre-existing disease

\section{Keep difficult airway cart ready during extubation}

Patient fully awake and obeying commands

Consider CPAP/HFNC O,
$3 \mathrm{Ss}$

Surgical cause for airway compromise** Suspected airway oedema Suspected airway collapse

Flow Chart 2 AIDAA Guidelines for the management of anticipated difficult extubation [22]

\section{Post- procedure plan}

1. Treat airway oedema if suspected

2. Monitor for any complications

3. Counseling and documentation 


\subsubsection{Airway Problems}

In the post-anaesthesia care unit (PACU) the close monitoring of complications should be done, which can lead to airway obstruction such as soft-tissue swelling and formation of haematoma. Capnography may provide an earlier warning of serious problems than pulse oximetry when supplemental oxygen is being administered. Even in uncomplicated cases, the effects of residual anaesthetic agents on airway physiology are more pronounced in patients with MMF who may experience increased resistance to breathing.

\subsubsection{Post-Operative Haematoma}

Haematoma formation in the early postoperative period is an uncommon but potentially airway-threatening complication of some maxillofacial operations, notably neck surgery, thyroid resections and floor of mouth surgery. The rate at which airway compromise occurs is variable. Emergency decompression of the haematoma may be even done at the bedside. It involves removing the clips/sutures and manually evacuating the haematoma with a Yankaur sucker. However, this may not alleviate the airway obstruction adequately due to oedema that results from venous congestion. The airway needs to be secured urgently. The method of securing the airway should take into consideration information from the initial operation, but it is expected to be more challenging and may require expert airway management.

\subsubsection{Nausea and vomiting [23]}

Factors that predispose to PONV include the female gender, a history of motion sickness, a low threshold for nausea, preoperative anxiety, obesity and gastric distension. Volatile anaesthetic agents, nitrous oxide, opioid usage and intubation have also been implicated as has prolonged surgery, early oral intake and certain types of surgery, including maxillofacial surgery.

Vomiting in patients with MMF is dangerous as it may predispose to aspiration. If the jaws are wired together, there must be wire cutters immediately available, which accompany the patient from theatre, to the PACU, and also to the ward.

Elastics in MMF can be cut easily with ordinary scissors.

PONV prophylaxis is best given round the clock for the first $24 \mathrm{~h}$ and longer if opioids continue to be used. If treatment for PONV is required within $6 \mathrm{~h}$ of PONV prophylaxis, it should ideally be with a different class of anti-emetic drug to that used initially (See Appendix I).

\subsubsection{Analgesia [23-25]}

After orthognathic surgery immediate postoperative pain is often not severe, and this is contributed to by the generous intra-operative use of local anaesthesia. A multi-modal analgesia approach should also be utilized perioperatively by combining opioids with paracetamol and non-steroidal antiinflammatory drugs towards the end of the case.

Patient Control Analgesia (PCA): It allows the patient to self-administer intravenous analgesics by means of a computer-controlled pump. It administers the pre-programmed dose on demand by the individual.

\subsection{Case Scenarios}

Case 1: Problem-Based Learning Tool

Case 2: Multiple choice questions

\subsubsection{Case 1: Cleft Palate}

A 10-month-old child presents for surgery with a cleft palate

1. What are the problems special for cleft babies

- Regurgitation and repeated aspiration

- Repeated respiratory infections

- Airway obstruction

- Malnutrition/anaemia

- Associated syndromes

2. What are the important features to look for during the pre- anaesthetic/presurgical evaluation? History-

- Feeding-Type of food, difficulty in swallowing, nasal regurgitation

- Repeated respiratory infections and/or hospitalization

- Airway obstruction especially during sleep (snoring or sleep apnoea) — position adopted when asleep

- Previous surgery as for repair of the cleft lip

- Episodes of cyanosis or referral to a cardiologist

- Birth history with details of ventilator requirements or neonatal ICU admission,

- Milestones and immunization

Examination

- Body weight, signs of malnutrition, dehydration or anaemia

- Pulse, BP and Room air saturation, temperature to be recorded

- Mouth opening, neck extension

- Respiratory system - signs of respiratory infection

- Rule out cardiovascular involvement

- Look for associated syndromes the most common of which are Pierre Robin Sequence, Treacher Collins syndrome and Down syndrome. 
Investigations

- Hb,- nutritional anaemia is common

- Complete blood picture-white blood counts may be elevated due to repeated infections

- Bleeding parameters - to rule out coagulopathies

- Chest X-ray if repeated chest infections or respiratory signs present on clinical examination

- Cardiology consult: ECG and ECHO cardiogram if cardiac involvement suspected

In addition:

- Meet the parents, allay their anxiety and give full explanation of procedure.

- Explain fasting guidelines with details of timing of feeds

- Solids and milk feeds $6 \mathrm{~h}$ prior to surgery and clear fluids, especially with glucose/sugar, $2 \mathrm{~h}$ prior to surgery

- Document informed consent form.

- Discuss procedure and requirements with primary surgeon

3. What preparations are necessary on day of surgery? Preparation: On day of surgery

- Ensure adequate help

- Ensure operating room temperature is not too cold

- Check Equipment and Drugs: Suction, Oxygen, Airway, Pharmacy (the pneumonic SOAP helps)

- Check anaesthesia machine

- Ensure that the difficult airway cart with rescue devices is available

Monitors: ECG, NIBP, Pulse Oximeter, $\mathrm{EtCO}_{2}$, and airway pressure (once intubated)

4. What are the problems that can present during anaesthesia?

- Induction-intravenous or inhalational?

- Mask ventilation may be difficult especially in cases of facial cleft

- Laryngoscopy. The larynx is anterior, the tongue relatively large and laryngoscope tends to slip into the cleft

- Position of the patient in this case the trunk of the baby should be supported on a large pillow with the neck hyperextended and head stabilized within a head ring.

- Sharing the airway with the surgeon

- kinking of tube when the gag is placed

- accidental extubation during positioning of the baby or removal of the gag

- tube may be pushed endobronchially resulting in one lung ventilation when gag is applied

- throat pack/other packs may be left behind after surgery causing airway obstruction
- Intraoperative monitoring + access to the monitors difficult-so ensure they are fixed well and working well before patient is draped

- Access to the patient difficult, so make sure that intravenous access is good and fixed well before draping

- Analgesics like paracetamol and short-acting opioids like fentanyl may be used.

- Extubation is often more difficult than intubation. If there is any query regarding obstruction to the airway, place a nasopharyngeal airway and a tongue stitch prior to extubation.

5. Could there be any problems post operatively? If so enumerate them.

- Bleeding.

- Airway obstruction.

- Laryngospasm or post extubation stridor due to oedema of the upper airway: Treat with CPAP, humidified oxygen, aerosolized adrenaline, intravenous dexamethasone and nebulized steroids.

- Bronchospasm: Bronchodilators, oxygen and adrenaline, if severe.

- Aspiration: Suck out the mouth, nurse laterally, start antibiotics and chest.

- Physiotherapy along with nebulized bronchodilators.

- Electrolyte imbalance/hypoglycaemia: Send blood for investigations and correct

- Hypothermia/hyperthermia

- Seizures/Anticonvulsants: Rule out hyperthermia (tepid sponging and paracetamol) and hyponatraemia (intravenous normal saline).

\subsubsection{Case-2: Polytrauma with Facial Injuries}

A 27-year-old male presented with the history of polytrauma following a road traffic accident. He gives a history of brief period of loss of consciousness following injury. No history of seizures, or other comorbidities. On examination, his GCS was $15 / 15$, and he was haemodynamically stable. Airway examination revealed restricted mouth opening of just one finger breadth, a short neck and a lacerated wound on the lower lip and chin with emphysema on the left side of the face extending into submandibular region. Cardiovascular, respiratory, abdominal and central nervous system examination was unremarkable. Blood investigations revealed increased CPK.

CT brain and spine showed a 3.5-mm extra-dural haemorrhage in the right temporal region, right frontal haemorrhagic contusion, an undisplaced fracture of the body of the mandible in bilateral parasymphyseal region with a displaced right zygomatic arch, a comminuted, mildly displaced fracture of right squamous temporal bone and undisplaced fracture of superior facet of C5 vertebra (Fig. 7.16). 


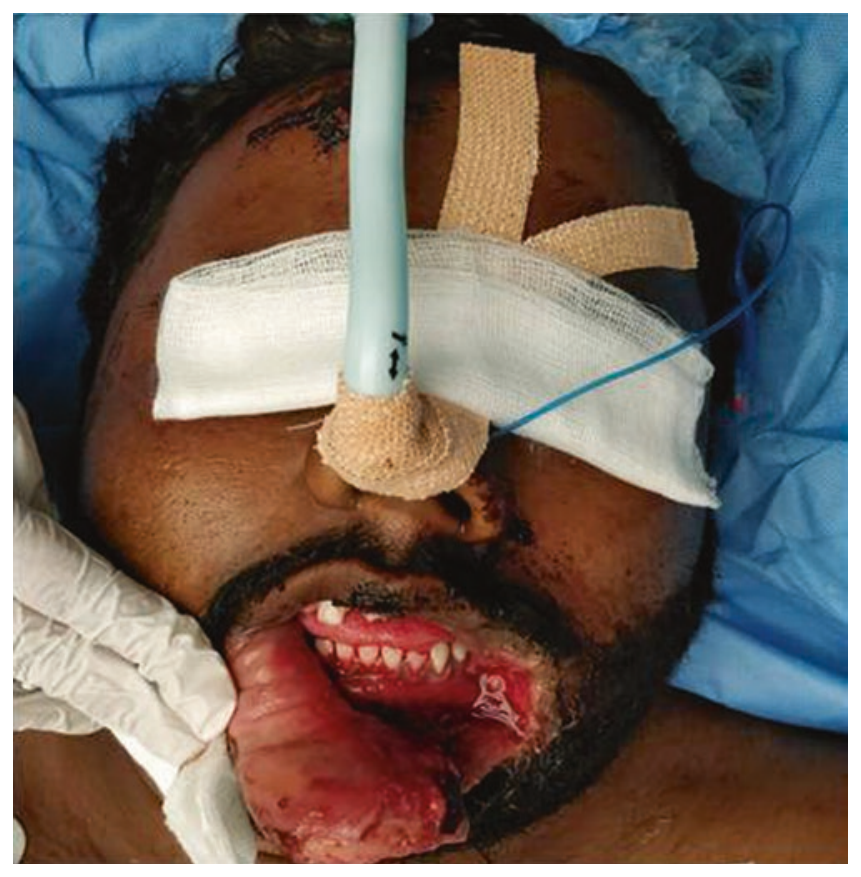

@Association of Oral and Maxillofacial Surgeons of India

Fig. 7.16 Photograph of a patient with polytrauma \& facial injuries

\section{Questions:}

1. Following things are true about blunt trauma to face EXCEPT

a. Cervical spine injury occurs in up to $10 \%$ of cases

b. Drugs and alcohol could be a contributing factor

c. Potential for injuries to other organs \& massive blood loss

d. Injuries in children are less severe than in adults

Answer: d) Injuries in children are usually more severe than in adults

2. In this patient, following could be cause of restricted mouth opening EXCEPT:
a. Fracture Mandible
b. Presence of trismus
c. Cervical collar
d. \# of superior facet of C5 vertebra

Answer: d) Fracture of Cervical vertebra usually does not restrict mouth opening

3. What is the reason for the presence of subcutaneous emphysema of the face in this patient?
a. Pneumothorax
b. Tracheal injury
c. Soft-tissue injury
d. \# involving sinuses

Answer: d) Fractures involving air-filled sinuses around face can cause subcutaneous emphysema
4. What is the EXCEPTION to the bedside predictors of difficult intubation in a case like this?
a. Receding mandible
b. Facial injury
c. Edentulous
d. Cervical collar

Answer: c) Absence of teeth usually causes difficulty in ventilation rather than difficulty in intubation

5. Which of the following is most useful for detection of Extradural haematoma?
a. CT scan of head
b. MRI scan of head
c. X-Ray Skull
d. Careful clinical examination

Answer: a) A CT scan is more appropriate investigation in an emergency

6. What would be your preferred method for securing the airway?

a. Conventional laryngoscopy with oral endotracheal intubation.

b. Conventional laryngoscopy with nasal endotracheal intubation.

c. Fibre optic bronchoscopy with nasal intubation.

d. Conventional laryngoscopy with manual in line stabilization with nasal endotracheal intubation.

Answer: b) Conventional laryngoscopy with nasal endotracheal intubation

7. What would be your preferred airway device for securing the airway?
a. Regular endotracheal tube
b. Nasal RAE tube
c. Oral RAE tube
d. Reinforced cuffed endotracheal tube

Answer: b) Nasal RAE tube.

8. What do you anticipate with respect to airway in this case?
a. Difficult mask ventilation
b. Difficult laryngoscopy
c. Both a) and b)
d. Normal ventilation and laryngoscopy.

Answer: c) Both difficult mask ventilation and laryngoscopy.

9. The following monitoring would be useful during surgery in a case like this EXCEPT:
a. Invasive arterial pressure
b. Urine output
c. Central venous pressure monitoring
d. BIS monitoring

Answer: c) Central venous pressure monitoring would not add any additional value in a case like this

10. Where would you shift this patient after the surgery?
a. General ward
b. Special ward 


\section{c. ICU \\ d. HDU}

Answer: d). HDU will be an appropriate place to monitor this patient post operatively

11. What is the most suitable method for pain relief in this patient?
a. NSAIDs
b. Nerve blocks
c. Tramadol
d. PCA Fentanyl

Answer: d) PCA fentanyl will be an appropriate choice as patient has multiple injuries and is being monitored in HDU.

12. Which intravenous fluid is appropriate during the surgery for this patient?
a. Dextrose-containing solutions
b. Balanced salt solutions
c. Hypertonic saline
d. Colloids

Answer: b) Balanced salt solutions

\section{Appendix I: Dosage of common Drugs}

\begin{tabular}{|c|c|c|}
\hline Drug & Action/group & Dosage \\
\hline Dexmedetomidine ${ }^{11}$ & $\alpha_{2}$-adrenergic-agonists & $\begin{array}{l}\text { Bolus: } 1 \mathrm{mcg} / \mathrm{kg} \text { over } 10 \mathrm{mins} \text { followed by continuous infusion of } 0.2 \text { - } \\
1 \mathrm{mcgs} / \mathrm{kg} / \mathrm{h}\end{array}$ \\
\hline Atropine & Anticholinergic & $0.5 \mathrm{mg} \mathrm{I} . \mathrm{V}$ \\
\hline Glycopyrrolate & Anticholinergic & $\begin{array}{l}\text { Antisialagogue: } 3-4 \mu / \mathrm{kg} \text { I. M } 30-60 \text { min prior. } \\
\text { Bradycardia: } 0.1 \mathrm{mg} \text { I.V repeated every } 2 \text { to } 3 \text { mins. }\end{array}$ \\
\hline Topical Lignocaine & Local anaesthetic & $\begin{array}{l}\text { Maximum safe dose: Adults: } 9-10 \mathrm{mg} / \mathrm{kg} \text { lean body weight. } \\
\text { Paediatrics: } 4.5 \mathrm{mg} / \mathrm{kg}\end{array}$ \\
\hline Dexamethasone & $\begin{array}{l}\text { Adrenocortical steroid: } \\
\text { Anti-inflammatory dose } \\
\text { Antiemetic [14] }\end{array}$ & $\begin{array}{l}0.1-0.2 \mathrm{mg} / \mathrm{kg} \\
4-5 \mathrm{mg} \mathrm{I} . \mathrm{V}\end{array}$ \\
\hline Ondansetron & Antiemetic-Serotonin antagonist & $0.1-0.2 \mathrm{mg} / \mathrm{kg}$ \\
\hline $\begin{array}{l}\text { Prochlorperazine } \\
\text { (Stemetil) }\end{array}$ & $\begin{array}{l}\text { Antiemetic-Dopamine receptor } \\
\text { antagonist }\end{array}$ & $0.25 \mathrm{mg} / \mathrm{kg}$ \\
\hline Tranexamic acid [15] & Antifibrinolytic & $\begin{array}{l}\text { 1. Bolus dose: } 15 \mathrm{mg} / \mathrm{kg} \text { can be repeated every } 6-8 \mathrm{~h} \text { (prior to incision) or } \\
\text { 2. Continuous infusion during the surgery: } 1 \mathrm{~g} \text { over } 10 \text { mins followed by } 1 \\
\text { gm over } 8 \mathrm{~h} \text { or } 20-25 \mathrm{mg} / \mathrm{kg} \text { followed by } 1-2 \mathrm{mg} / \mathrm{kg} / \mathrm{h} \text { ). }\end{array}$ \\
\hline
\end{tabular}

\section{Appendix II: Commonly Used Drugs for Controlled Hypotension}

\begin{tabular}{|c|c|}
\hline Drug & Administration and Dose \\
\hline $\begin{array}{l}\text { Vasodilators: } \\
\text { SNP }\end{array}$ & $\begin{array}{l}\text { Infusion: } \\
\text { Up to } 1.5 \mathrm{mcgs} / \mathrm{kg} / \mathrm{min}\end{array}$ \\
\hline NTG & Infusion: - 0.5-2 $\mathrm{mcgs} / \mathrm{kg} / \mathrm{min}$ \\
\hline $\begin{array}{l}\text { Adreno-receptor } \\
\text { antagonists: } \\
\text { Selective: } \\
\partial \text {-selective: } \\
\text { Phentolamine }\end{array}$ & Intermittent boluses: $2-5 \mathrm{mg}$. \\
\hline $\begin{array}{l}\text { B-selective: } \\
\text { Metoprolol }\end{array}$ & Intermittent boluses: $0.1 \mathrm{mg} / \mathrm{kg}$. \\
\hline Esmolol & $\begin{array}{l}\text { Loading: } 1 \mathrm{mg} / \mathrm{kg} \text { over } 1 \mathrm{~min} \text { followed by } \\
\text { Infusion: } 0.5-1 \mathrm{mg} / \mathrm{kg} / \mathrm{h} \text {. }\end{array}$ \\
\hline $\begin{array}{l}\text { Non-selective: } \\
\text { Labetolol }\end{array}$ & $\begin{array}{l}\text { Boluses: } 0.25 \mathrm{mg} / \mathrm{kg} \text { followed by infusion: } \\
0.5-2 \mathrm{mg} / \mathrm{min}\end{array}$ \\
\hline $\begin{array}{l}\alpha_{2} \text {-adrenergic-agonists: } \\
\text { Clonidine }\end{array}$ & Infusion/boluses: $1 \mathrm{mcgs} / \mathrm{kg}$ \\
\hline Dexmedetomidine & $\begin{array}{l}\text { Bolus: } 1 \mathrm{mcgs} / \mathrm{kg} \text { over } 10 \mathrm{mins} \text { followed } \\
\text { by infusion of } 0.3-1 \mathrm{mcg} / \mathrm{kg} / \mathrm{hr} \text {. }\end{array}$ \\
\hline Magnesium sulphate & Bolus: $20-60 \mathrm{mg} / \mathrm{kg}$ \\
\hline
\end{tabular}

\section{Advantages}

Potent venous and arteriolar

dilatation.

Venodilator

Vasodilatation.

Heart rate control

Vasodilatation + heart rate control

Vasodilatation with heart rate control. Analgesic properties

Vasodilatation with heart rate control. Analgesic properties

Vasodilatation with heart rate control. Analgesic properties
Disadvantages

Reflex tachycardia.

Rebound hypertension.

Tachyphylaxis.

Cyanide toxicity.

Reflex tachycardia.

Tachyphylaxis.

Bronchospasm.

Negatively inotropic

Bronchospasm

Post op sedation.

Rebound hypertension.

Post op sedation.

Prolonged neuromuscular block 


\section{Appendix III: Handover Form Used for Inter Hospital Transfer}

Patient details
\begin{tabular}{|l|l|l|l|}
\hline Name: & Age: & Sex: M/F & MRN No: \\
\hline Diagnosis:
\end{tabular}

\begin{tabular}{|l|}
\hline Brief clinical history: \\
\hline Clinical summary written by: \\
\hline
\end{tabular}

\begin{tabular}{|l|l|}
\hline \multicolumn{2}{|l|}{ Reason for transfer: } \\
\hline Transfer out hospital: & Referring doctor: \\
\hline Transfer in hospital: & Accepting doctor: \\
\hline Inter - hospital transfer consent taken: Y/N \\
\hline
\end{tabular}

\section{Vitals before transfer:}

\begin{tabular}{|l|l|l|}
\hline HR: $/ \mathrm{min}$ & BP: $\mathrm{mm} \mathrm{Hg}$ & RR: \\
\hline SpO2: $\%$ & O2: I/min & AVPU score: \\
\hline \multicolumn{2}{|l|}{ Airway: Intubated and assisted / Intubated and spontaneous / Not } \\
intubated \\
Patent IV access: \\
Fluid on flow: \\
Medications on flow: \\
Monitors connected: ECG / Pulse oximetry / NIBP / Others \\
\hline
\end{tabular}

Transfer details:

\begin{tabular}{|l|l|}
\hline Departure time: & Arrival time : \\
\hline
\end{tabular}

Duration of Transfer:

Accompanied by:

Critical events during transfer:

Vitals on arrival/admission:

\begin{tabular}{|l|l|l|}
\hline HR: $/ \mathrm{min}$ & BP: $\mathrm{mm} \mathrm{Hg}$ & RR: \\
\hline SpO2: \% & O2: I/min & AVPU score: \\
\hline \multicolumn{2}{|l|}{ Airway: Intubated and assisted / Intubated and spontaneous / Not } \\
intubated \\
Patent IV access: \\
Fluid on flow: \\
Medications on flow: \\
Monitors connected: ECG / Pulse oximetry / NIBP / Others \\
\hline
\end{tabular}

\section{Handover details:}

Clinical summary: $\mathrm{Y} / \mathrm{N}$

Patient records: $\mathrm{Y} / \mathrm{N}$

Investigations: $\mathrm{Y} / \mathrm{N}$

\begin{tabular}{|l|l|}
\hline \multicolumn{1}{|c|}{ Handing Over Doctor } & \multicolumn{1}{c|}{ Taking over doctor: } \\
Name: & Name: \\
Sign: & Sign: \\
Date \& time: & Date \& time: \\
\hline
\end{tabular}




\section{Appendix IV: Inter-Hospital Transfer Guidelines}

The transfer of the patient to a Centre where intensive care is available may sometimes be required if the facilities at the current hospital are inadequate. Most of these patients are critically ill and need the utmost care and planning to ensure safety during transfer. It is the responsibility of the referring team (surgeon as well as anaesthesiologist) to ensure a safe handover to the new treating team of doctors.

The following guidelines may be used to develop local protocols for inter-hospital transfer.

- The decision to transfer should be done by the treating team of doctors.

- Choose the appropriate hospital.

- The patient's family should be counselled by the treating doctor for the reason of transfer.

- Obtain consent from the patient's family after explaining the need as well as the risks involved in transfer.

- The administrative coordination between the two hospitals, e.g. checking the availability of beds, required doctors, equipment, etc. should be performed telephonically. The verbal consent to accept the patient by the destination hospital authorities should be done and documented.

- A short summary of the patient's clinical condition and handover document should be prepared.

- The transfer team should be identified. It should comprise at least 2 members who are adequately trained in handling sick patients, e.g. while transferring an intubated patient, the team should be trained in managing intubated patients. At least one doctor (preferably an anaesthetist) should accompany/supervise the patient during transfer especially sick patients.

- The departure checklist should include confirming the following:

- Ambulance services.

- Sufficient oxygen supply.

- Shifting trolley.

- Battery backup for equipment.

- Mode of ventilation (for intubated patients).

- Adequate monitoring (ECG, pulse oximetry, blood pressure).

- Resuscitative medications (prefilled syringes).

- Required paperwork-clinical summary, patient records and investigations.

- Knowledge of destination hospital location and contact numbers.

- Clinical stability of the patient should be confirmed before shifting.

- Patient should be stabilised before transfer. The following should be confirmed just before transfer-a patent IV line, a patent airway access, a functioning monitor with adequate battery backup. In case of an intubated patient -DO NOT EXTUBATE just prior to transfer.

- Note and record vital signs just before transfer.

- During transfer the vitals should be monitored continuously and documented frequently.

- Anticipation of problems during transfer and preparedness will help ensure safe transfer.

- Upon reaching the destination hospital, the transferring team should ensure that the patient is safely shifted to the desired critical care area and the hand-over formalities completed.

\section{References}

1. Allman K, Wilson I. Oxford handbook of Anaesthesia. 3rd ed. Oxford, UK: Oxford University Press; 2011.

2. Shaw I, Kumar C, Dodds C, editors. Oxford textbook of Anaesthesia for Oral and maxillofacial surgery. Oxford, UK: Oxford University Press; 2010.

3. Sherwood MW, Douketis JD, Patel MR, Piccini JP, Hellkamp AS, Lokhnygina Y, et al. Outcomes of temporary interruption of rivaroxaban compared with warfarin in patients with nonvalvular atrial fibrillation: results from the rivaroxaban once daily, oral, direct factor Xa inhibition compared with vitamin $\mathrm{K}$ antagonism for prevention of stroke and embolism trial in atrial fibrillation (ROCKET AF). Circulation. 2014;129(18):1850-9.

4. Popat M. Difficult airway management. Oxford, UK: Oxford University Press; 2009.

5. American College of Surgeons Committee on Trauma. Advanced trauma life support for doctors. 6th ed. Chicago: American College of Surgeons; 1997.

6. Jacob R. Recognition and management of the difficult paediatric airway. In: Jacob R, editor. Understanding paediatric anaesthesia. 3rd ed. India: Wolters Kluwer (India); 2015. p. 184-94.

7. Kheterpal S, Martin L, Shanks AM, Tremper KK. Prediction and outcomes of impossible mask ventilation: a review of 50,000 anesthetics. Anesthesiology. 2009;110:891-7.

8. Reed MJ, et al. Can an airway assessment score predict difficulty at intubation in the emergency department? Emerg Med J. 2005 Feb;22:99-102.

9. Teasdale G, Jennett B. Assessment of coma and impaired consciousness. A practical scale. Lancet. 1974;2:81-4.

10. Mackay CA, Burke DP, Burke JA, Porter KM, Bowden D, Gorman D. Association between the assessment of conscious level using the AVPU system and the Glasgow coma scale. Pre-Hospital Immediate Care. 2000;4:17-9.

11. Chopra P, Dixit MB, Dang A, Gupta V. Dexmedetomidine provides optimum conditions during awake fiberoptic intubation in simulated cervical spine injury patients. J Anaesthesiol Clin Pharmacol. 2016;32:54-8.

12. Ramkumar V. Preparation of the patient and the airway for awake intubation. Indian J Anaesth. 2011;55(5):442-7.

13. Pavlakovic L, Lee G. Anaesthesia for maxillofacial surgery. Anaesthesia and intensive care medicine. 2014;15(8):379-84.

14. De Oliveira GS Jr, Castro-Alves LJ, Ahmas S, Kendall MA, RJ MC. Dexamethasone to prevent postoperative nausea and vomiting: an updated meta-analysis of randomized controlled trials. Anesth Analg. 2013 Jan;116(1):58-74.

15. WHO model list of essential drugs 17th list; March, 2011. http:// www.who.int/medicines/publications/essentialmedicines/en/index. html 
16. Rossaint R, Bouillon B, Cerny V, Coats TJ, Duranteau J, FernándezMondéjar E, et al. The European guideline on management of major bleeding and coagulopathy following trauma: fourth edition. 2016;20(1):100.

17. Rodrigo C. Induced hypotension during anesthesia with special reference to orthognathic surgery. Anesth Prog. 1995;42(2):41-58.

18. Bajwa S, Kaur J, Kulshrestha A, Haldar R, Sethi R, Singh A. Nitroglycerine, esmolol and dexmedetomidine for induced hypotension during functional endoscopic sinus surgery: A comparative evaluation. 2016;32(2):192-197.

19. Sajedi P, Rahimian A, Khalili G. Comparative evaluation between two methods of induced hypotension with infusion of Remifentanil and labetalol during sinus endoscopy. J Res Pharm Pract. 2016;5(4):264-71.

20. Morosan M, Parbhoo A, Curry N. Anaesthesia and common oral maxillo-facial emergencies. Continuing education in anaesthesia. Critical Care and Pain. 2012;12:5.

21. McDermott PJC. Reflex bradycardia in facial surgery. J Oral Maxillofac Surg. 1990;48(9):1015-6.

22. Kundra P, Garg R, Patwa A, Ahmed SM, Ramkumar V, Shah A, Divatia JV, Shetty SR, Raveendra US, Doctor JR, Pawar DK,
Singaravelu R, Das S, Myatra SN. All India difficult airway association 2016 guidelines for the management of anticipated difficult extubation. Indian J Anaesth. 2016;60(12):915-21. https://doi. org/10.4103/0019-5049.195484.

23. Patel PK, Morris DE, Gassman A. Complications of orthognathic surgery. J Craniofac Surg. 2007;18(4):975-85.

24. Beck JI, Johnston KD. Anaesthesia for cosmetic and functional maxillofacial surgery. Continuing Education in Anaesthesia Critical Care \& Pain. 2014;14(1):38-42.

25. Lupori JP, Van Sickels JE, Holmgreen WC. Outpatient orthognathic surgery: review of 205 cases. J Oral Maxillofac Surg. 1997;55:558-63.

\section{Additional Reading (Sub Mental Intubation)}

Hernández AF. Sub-mental vs. retromolar intubation. Anaesthesia. 2006 Nov;61(11):1123-4.

Altemir FH, Montero SH, Peña MM. About submental intubation. Anaesthesia. 2003 May;58(5):496-7.

Open Access This chapter is licensed under the terms of the Creative Commons Attribution 4.0 International License (http://creativecommons. org/licenses/by/4.0/), which permits use, sharing, adaptation, distribution and reproduction in any medium or format, as long as you give appropriate credit to the original author(s) and the source, provide a link to the Creative Commons license and indicate if changes were made.

The images or other third party material in this chapter are included in the chapter's Creative Commons license, unless indicated otherwise in a credit line to the material. If material is not included in the chapter's Creative Commons license and your intended use is not permitted by statutory regulation or exceeds the permitted use, you will need to obtain permission directly from the copyright holder. 